Article

\title{
Intermediate-Salinity Systems at High Altitudes in the Peruvian Andes Unveil a High Diversity and Abundance of Bacteria and Viruses
}

\author{
Hugo Gildardo Castelán-Sánchez ${ }^{1}{ }^{\circledR}$, Paola Elorrieta ${ }^{2}$, Pedro Romoacca ${ }^{3}$, Arturo Liñan-Torres ${ }^{1}$, \\ José Luis Sierra ${ }^{4}$, Ingrid Vera ${ }^{3}$, Ramón Alberto Batista-García ${ }^{1}{ }^{10}$, Silvia Tenorio-Salgado ${ }^{5}$, \\ Gabriel Lizama-Uc ${ }^{5}$, Ernesto Pérez-Rueda ${ }^{6,7}$ (D), María Antonieta Quispe-Ricalde ${ }^{2, *}$ \\ and Sonia Dávila-Ramos ${ }^{1, * \mathbb{D}}$ \\ 1 Centro de Investigación en Dinámica Celular, Instituto de Investigación en Ciencias Básicas y Aplicadas, \\ Universidad Autónoma del Estado de Morelos, Cuernavaca, Morelos C.P. 62209, Mexico; \\ hcastelans@gmail.com (H.G.C.-S.); arturo211t@gmail.com (A.L.-T.); rabg@uaem.mx (R.A.B.-G.) \\ 2 Departamento de Biología, Facultad de Ciencias, Universidad Nacional de San Antonio Abad del Cusco, \\ Cusco C.P. 0800, Peru; pao91827364@gmail.com \\ 3 Departamento de Farmacia y Bioquímica, Facultad de Ciencias de la Salud, Universidad Nacional de San \\ Antonio Abad del Cusco, Cusco C.P. 0800, Peru; ordep.rh1211@gmail.com (P.R.); iveraf@yahoo.es (I.V.) \\ 4 Escuela de Postgrado, Universidad Nacional de San Antonio Abad del Cusco, Cusco C.P. 0800, Peru; \\ 1sierrah77@gmail.com \\ 5 Tecnológico Nacional de México, Instituto Tecnológico de Mérida, Mérida, Yucatán C.P. 97000, Mexico; \\ s.tenorio.salgado@gmail.com (S.T.-S.); gabriel.lizama29@gmail.com (G.L.-U.) \\ 6 Instituto de Investigaciones en Matemáticas Aplicadas y en Sistemas, Sede Mérida, Universidad Nacional \\ Autónoma de México, Unidad Académica de Ciencias y Tecnología, Mérida, Yucatán C.P. 97302, Mexico; \\ eprueda@gmail.com \\ 7 Centro de Genómica y Bioinformática, Facultad de Ciencias, Universidad Mayor, Providencia, \\ Santiago C.P. 7500000 , Chile \\ * Correspondence: antonieta.quispe@unsaac.edu.pe (M.A.Q.-R.); sonia.davila@uaem.mx (S.D.-R.); \\ Tel.: +52-(777)-3297000 (ext. 3276) (S.D.-R.)
}

Received: 11 September 2019; Accepted: 26 October 2019; Published: 5 November 2019

\begin{abstract}
Intermediate-salinity environments are distributed around the world. Here, we present a snapshot characterization of two Peruvian thalassohaline environments at high altitude, Maras and Acos, which provide an excellent opportunity to increase our understanding of these ecosystems. The main goal of this study was to assess the structure and functional diversity of the communities of microorganisms in an intermediate-salinity environment, and we used a metagenomic shotgun approach for this analysis. These Andean hypersaline systems exhibited high bacterial diversity and abundance of the phyla Proteobacteria, Bacteroidetes, Balneolaeota, and Actinobacteria; in contrast, Archaea from the phyla Euryarchaeota, Thaumarchaeota, and Crenarchaeota were identified in low abundance. Acos harbored a more diverse prokaryotic community and a higher number of unique species compared with Maras. In addition, we obtained the draft genomes of two bacteria, Halomonas elongata and Idiomarina loihiensis, as well as the viral genomes of Enterobacteria lambda-like phage and Halomonas elongata-like phage and 27 partial novel viral halophilic genomes. The functional metagenome annotation showed a high abundance of sequences associated with detoxification, DNA repair, cell wall and capsule formation, and nucleotide metabolism; sequences for these functions were overexpressed mainly in bacteria and also in some archaea and viruses. Thus, their metabolic profiles afford a decrease in oxidative stress as well as the assimilation of nitrogen, a critical energy source for survival. Our work represents the first microbial characterization of a community structure in samples collected from Peruvian hypersaline systems.
\end{abstract}


Keywords: Peruvian Andes; metagenomics; intermediate salinity; microbiome; virus

\section{Introduction}

Millions of years ago (80-110 million years), the ocean covered the central region of Peru; during the formation of the Andes mountains, these marine waters remained inland and, by evaporation, formed deposits of salt in ponds. Different hypersaline water systems are distributed throughout Peru, such as the salterns of the Acos system and the brines from Maras, two thalassohaline environments located in the Andes mountains in southeast Peru. These two systems have not received much study. Acos is located in the district of Acomayo (southeast Peru) at an altitude of $2852 \mathrm{~m}$ above sea level, while Maras is located in the district of Urubamba at an altitude of $3380 \mathrm{~m}$ and is composed of 3000 small shallow ponds that form terraces on the slope of the mountain Qaqawiñay (a Quechua word meaning eternal rock) [1,2].

The hypersaline ecosystems are characterized by alkalinity and low oxygen concentrations [3-6]. Hypersaline aquatic environments are classified into two main categories: (1) thalassohaline environments, which result from the evaporation of seawater and contain a high concentration of $\mathrm{NaCl}$, neutral or slightly alkaline $\mathrm{pH}$, and a salinity exceeding that of seawater by a factor of 5-10; and (2) athalassohaline environments, which are not derived from seawater and contain high concentrations of ions such as $\mathrm{Mg}^{2+}$ or $\mathrm{Ca}^{2+}$ and a slightly acidic $\mathrm{pH}$ [3-6].

Aquatic hypersaline systems represent excellent models for the study of the ecology and diversity of microorganisms. Most saline systems are composed of ponds with different salinity gradients [7]. Microorganisms identified in hypersaline environments have been classified according to the concentration of salts in the environments they inhabit: weak halophiles $(1-3 \% \mathrm{NaCl})$, moderate halophiles $(3-15 \% \mathrm{NaCl})$, and extreme halophiles (more than $15 \% \mathrm{NaCl}$ ) [8]. In contrast, there is no generalized classification for saline environments, but they can be divided into low salinity (less than $10 \% \mathrm{NaCl}$ ), intermediate salinity $(10-20 \% \mathrm{NaCl}$ [ [9], and high salinity (higher than $20 \% \mathrm{NaCl}$ ) [10].

Regarding microbial communities that live in these ecosystems, a great diversity of microorganisms has been reported, in particular of the Halobacteriaceae family within the Archaea domain. For bacteria, the Halorhodospira, Salinibacter, Halomonas, Chromohalobacter, and Salicola genera are abundant; and eukaryotic organisms such as Artemia salina, Colpodella edax, and Dunaliella salina have been identified in low proportions [5,11-13]. In addition, a high diversity of haloviruses has been identified, at concentrations of $\geq 1 \times 10^{7}$ per $\mathrm{mL}$ in seawater, among which a few are cultivable [12].

In this work, the diversity of halophilic microorganisms and functional diversity were determined in two thalassohaline environments, Acos and Maras, that have physicochemical differences in salinity and $\mathrm{pH}$. We expected that these intermediate-salinity environments would contain a greater microbial diversity than high-salinity environments and with a particular microbial community structure given the high altitude. Thus, we consider that this analysis opens diverse opportunities to describe the microbial diversity and functional profile within the Peruvian hypersaline systems and will contribute to knowledge in these environments. This is the first characterization of a microbial community structure of intermediate salinity in samples collected from Peruvian high-altitude salterns.

\section{Materials and Methods}

\subsection{Sampling, DNA Extraction, and Sequencing}

Water (20 liters) was collected during the rainy season (January 2018) from two points where the water emerges in the mountain in two hypersaline systems located in Cusco, Peru. The first is in Maras $\left(13^{\circ} 57^{\prime} 59.3^{\prime \prime} \mathrm{S}, 71^{\circ} 05^{\prime} 65^{\prime \prime} \mathrm{W}\right)$, and the second is in Acos $\left(11^{\circ} 16^{\prime} 25^{\prime \prime} \mathrm{S}, 72^{\circ} 9^{\prime} 15^{\prime \prime} \mathrm{W}\right)$. The samples were obtained with sterilized tools and containers, and salinity and $\mathrm{pH}$ were measured in situ using a hand refractometer (Spectronic Instruments Inc., Rochester, NY, USA) and pH potentiometer (HANNA 
Instruments, Portugal), respectively. All samples were transported to the laboratory under refrigerated conditions, where liters of water were filtered through $0.22-\mu \mathrm{m}$ Millipore filters. The DNA was purified from the filters by using ZymoBIOMICS DNA kits (MoBio, West Carlsbad, CA, USA). The DNA concentration was determined using a NanoDrop 1000 spectrophotometer (Thermo Scientific), and fluorometry was measured using a Qubit 4 fluorometer (Invitrogen). The DNA was sequenced using the Illumina NextSeq 500 platform with the Nextera V2.0 kit (150 bp, $2 \times 75$ bases) at the Instituto de Biotecnología of Universidad Nacional Autónoma de México.

\subsection{Quality Control and Assembly}

The quality control of sequences was performed by FASTQC v0.11.4 software [14], and duplicated sequences were removed using CD-HIT-DUP v4.7 [15] with a maximum mismatch number of 0.03. Reads were assembled in contigs using MEGAHIT v1.1.2 [16] under default parameters in paired-end mode, and contigs of a minimum length of $1000 \mathrm{bp}$ were considered for further analysis.

\subsection{Microbial Community Taxonomic Assignments}

Taxonomic assignments were performed with software Kaiju v16.0. In addition, we used MetaGenome Rapid Annotation Subsystems Technology (MG-RAST v4.03) [17], which compares the assembly sequences with a comprehensive non-redundant database sourced from the National Center for Biotechnology Information (NCBI) databases, and SEED, which categorizes gene function into five levels of resolution. An expected value (E) cutoff of $10^{-5}$ was employed for taxonomic classifications. Raw data of Metagenomes have been deposited in MG-RAST with accession numbers: mgm4810306.3, mgm4808260.3, and mgm4810472.3.

For virus classification, the viral contigs were achieved with VirSorter v2 [18], and these contigs were classified with MEGAN v5.10.6. For fungi classification, the sequences were compared against a constructed database comprised of 35,296 complete and draft fungi genomes from NCBI. For both viruses and fungi, the best-scoring BLAST results with an E-value of $10^{-6}$ were parsed, and the taxonomic assignment was determined using MEGAN software [19]. The lowest common ancestor (LCA) method in MEGAN was used for taxonomic assignment, with the following parameters: minimum support of 2; minimum score of 50; top percent of 10 .

\subsection{Diversity Index}

The taxonomic profiles at the species level were used to calculate the diversity indices from all data, and different alpha diversity descriptors were obtained using the Phyloseq function in R v3.3.3 [20]. The beta diversity was determined by Bray-Curtis dissimilarity, and the sampling effort was evaluated through the rarefaction curves using a Vegan library implemented in R [21].

\subsection{Genome Reconstruction}

The reconstruction of the bacterial genome was directed to those species that had the highest abundance according to the taxonomic classification. The genomes were retrieved using the strategy fragment recruitments within Bowtie2 v2.2.6 [22]. The coverage was evaluated using BBmap v38.25 [23], and the consensus sequence was inferred using UGENE v1.31.1 [24]. For the reconstructed genome, the presence of contamination was evaluated using One Codex [25] and Genome Peek. Briefly, One Codex assigns an unknown nucleotide sequence for the identification of k-mers of fixed size k-31 in comparison with its own database. Genome Peek extracts the $16 \mathrm{~S}$ gene and $\mathrm{rad} A / \mathrm{rec} A$, rpoB, and groEL, the principal molecular markers, from a genome for taxonomic identification. The annotation was achieved using Prokka v1.12 [26] and visualized with Genome Atlas.

For viral sequences, identification was achieved by VirSorter [18] and was based on viral hallmark genes annotated as "major capsid protein," "portal," "terminase large subunit," "spike," "tail," "virion formation", and "coat," among others. The entire contig was considered viral if more than $80 \%$ of predicted genes on a contig had a viral signal. This software finds new viruses at different confidence 
levels, with scores of categories 1 to 4 , with 4 being the highest confidence level. Viral sequences identified within category 1 by VirSorter were visualized with the easyfig v2.2.2 tool and also assessed with the PHAge search tool (PHAST) [27].

Finally, contigs with lengths of $\geq 10 \mathrm{kbp}$ within category 2 ("quite sure") in VirSorter were translated into protein sequences and classified taxonomically using the vConTACT v2 software [28] with default parameters (https://bitbucket.org/MAVERICLab/vcontact), with the aim of classifying these possible new viruses.

\subsection{Binning for Putative Genomes}

Assembled contigs were clustered into bins or metagenome-assembled genomes (MAGs), using MaxBin v2.2.4 [29]. Briefly, MaxBin performs genome reconstruction from metagenomes based on two genomic characteristics, tetranucleotide frequencies and the level of bin coverage, using single-copy marker genes. The two metagenomes from Acos were used to recover the MAGs, which were later annotated with Prokka [26].

From the annotation of MAGs, the ribosomal sequences were extracted in single copy (L2, L3, L4, L5, L6, L14, L15, L16, L18, L22, L24, S3, S8, S10, S17, and S19), and then these sequences were aligned with those reported by Hung et al. [30] by using MAFFT v7.005 for taxonomic identification [31]. The phylogenetic analysis was performed using FastTree v2.1.7 [32], which considers an approximate maximum likelihood with 100 bootstrap replicates. Finally, the phylogenetic tree was displayed using ITOL [33].

\subsection{Functional Analysis and Biogeochemical Cycles}

Prodigal v2.6.3 [34] was used for predicting protein-coding genes in the assembled contigs by using the metagenomic mode, and the functional assignment was achieved using SUPERFOCUS [35], which contains the SEED database with an E-value of $10^{-5}$. From functional abundance tables, a heatmap using the ggplot2 library [36] and RColorBrewer library in R (www.ColorBrewer.org) was generated. Finally, microbial metabolic pathways involved in the biogeochemical cycles for carbon, sulfur, nitrogen, hydrogen, iron, and oxygen were identified using the Multigenomic Entropy-Based Score pipeline (MEBS v1) with a false-discovery rate of 0.0001 [37].

\section{Results and Discussion}

\subsection{Site Characterization and Field Sampling}

The water samples were collected from two locations in the district of Cusco, Peru. The first sample was collected from Maras; its $\mathrm{pH}$ was 7 and its salinity concentration was $23 \% \mathrm{NaCl}$ (Figure 1 ). This concentration was slightly lower than previously reported $(25 \% \mathrm{NaCl})$ in emergent water, whereas in the crystallizer ponds the concentration was higher $(30 \% \mathrm{NaCl})[1]$.

The second and third samples were collected from Acos, with a pH of 7.9 and $19 \%$ salinity (Table 1). The salinities of the thalossohaline water samples from Maras and Acos [1,2] were similar to levels in other solar salterns with intermediate salinity, such as Marine Saltern in Santa Pola, Spain (13-19\% $\mathrm{NaCl})[7,38]$ and Saltern in Isla Cristina, Spain $(21 \% \mathrm{NaCl})[38,39]$. In this regard, salterns exhibiting an intermediate salinity have been found to contain a greater diversity of microorganisms than salterns with higher salt concentration [38]; the concentration of $\mathrm{NaCl}$ defines the diversity and structure of the microbiome in these environments [40]. 


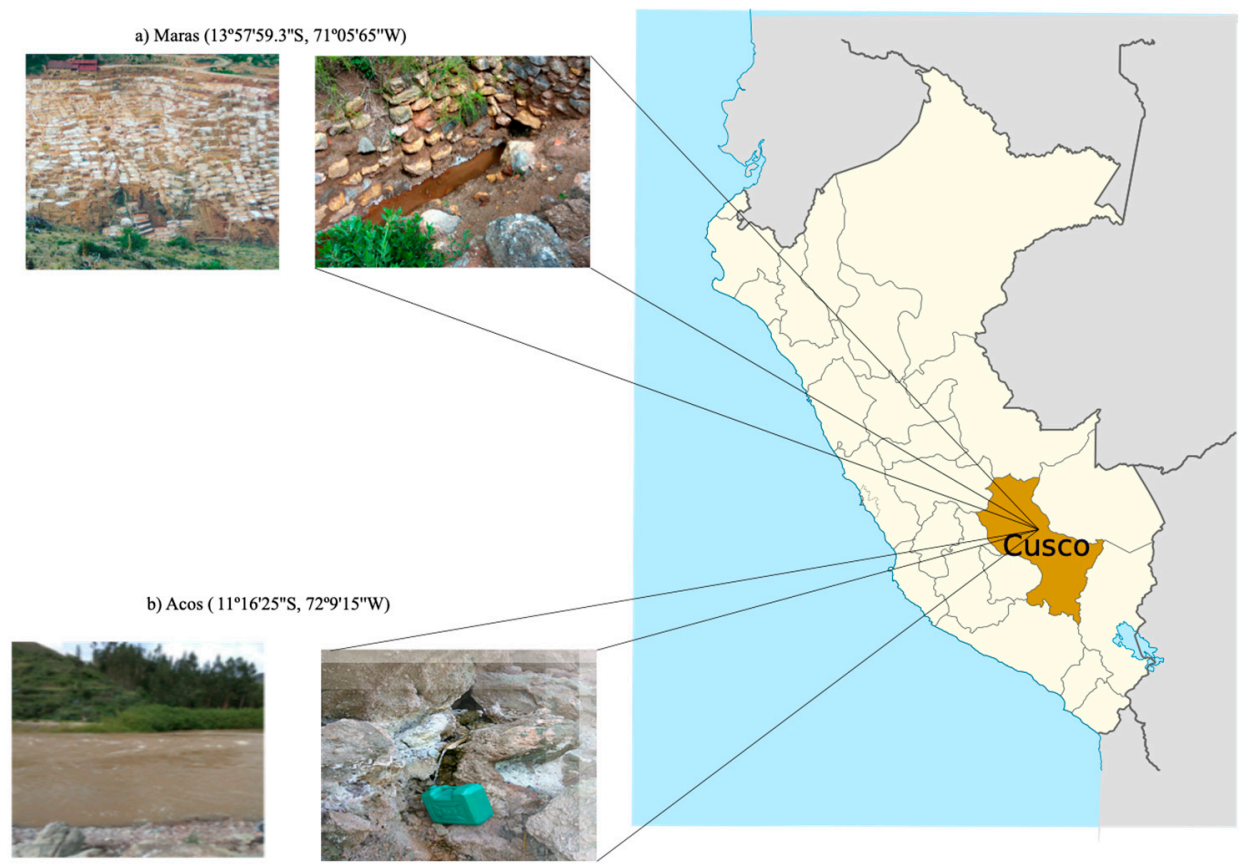

Figure 1. Location of the field sites in Cusco Peru. (a) Maras with 3000 shallow ponds. (b) Acos at the origin of the water.

Table 1. Sequence features of hypersaline metagenomes from Cusco, Peru.

\begin{tabular}{|c|c|c|c|c|c|c|c|c|c|c|}
\hline \multirow[t]{2}{*}{$\begin{array}{c}\text { Data } \\
\text { Set }\end{array}$} & \multirow[t]{2}{*}{ Salinity } & \multirow[t]{2}{*}{$\mathrm{pH}$} & \multirow{2}{*}{$\begin{array}{c}\text { Number of } \\
\text { Paired-End } \\
\text { Reads }\end{array}$} & \multirow{2}{*}{$\begin{array}{l}\text { Number } \\
\text { of Contigs } \\
\text { Assembled }\end{array}$} & \multicolumn{2}{|c|}{ Sequences } & \multicolumn{4}{|c|}{ Taxonomical Classification } \\
\hline & & & & & $\begin{array}{c}\text { Classified } \\
71 \%\end{array}$ & $\begin{array}{c}\text { Unclassified } \\
29 \%\end{array}$ & $\begin{array}{c}\text { Bacteria } \\
57 \%\end{array}$ & $\begin{array}{c}\text { Archaea } \\
14 \%\end{array}$ & $\begin{array}{c}\text { Eukarya } \\
2 \%\end{array}$ & $\begin{array}{c}\text { Viruses } \\
0.2 \%\end{array}$ \\
\hline$A \cos 2$ & $19 \%$ & 7.9 & $79,304,621$ & 256,430 & $71 \%$ & $29 \%$ & $57 \%$ & $16 \%$ & $2 \%$ & $0.2 \%$ \\
\hline Maras & $23 \%$ & 7.0 & $56,086,809$ & 2650 & $70 \%$ & $30 \%$ & $56 \%$ & $11 \%$ & $1 \%$ & $1.32 \%$ \\
\hline
\end{tabular}

\subsection{Community Structures of Intermediate Hypersaline Systems}

In order to analyze the diversity, abundance, and genes involved in metabolic profiles of samples from Maras and Acos, shotgun metagenomic sequencing was performed. Maras and Acos salterns can be considered environments at high altitude with intermediate salinity (according to the determined percentage of salt) (Table 1). However, salinity is not the only parameter that modifies the abundance and diversity of microorganisms present in these ecosystems; biogeographic patterns that may also have a role include altitude, remoteness of these environments, oxygen availability, alkalinity, altitude, and UV irradiation [41-43].

With the metagenomes obtained from the two locations, the general structure of the microbiome was determined. To this end, the sequences were classified with Kaiju (Table 1), and the results showed a high abundance of bacterial organisms ( $57 \%$ of the sequences), followed by Archaea ( 16\%). These results contrast with the abundance reported in crystallizer ponds in Maras, where the salinity of $>30 \% \mathrm{NaCl}$ showed a microbiota dominated by Archaea (80-86\% of total counts) with much lower percentages of Bacteria (10-13\%) [1].

The enrichment analysis of species and diversity in these sites, evaluated with Chao, Shannon, and Simpson indexes, revealed that Acos samples had a greater richness than Maras samples (Supplementary Table S1). These results correlated with the rarefaction curves, i.e., in Acos samples, the asymptotic distribution was reached, which indicates a greater diversity showing correlation to the other diversity indexes, whereas in the Maras sample the asymptote was not reached, since most of the contigs were assigned to Cutibacterium acnes, which is highly unlikely to reside in this environment and was considered a contaminant and was therefore eliminated from diversity curves and subsequent analyses. 
However, the remaining organisms present in this sample are halophilic, but as shown in the diversity curve it is necessary to perform new sampling to know the diversity in Maras (Supplementary Figure S1). In addition, the Bray-Curtis dissimilarity index was performed to evaluate the beta diversity, showing an index equal to 1, which indicates a different species composition between Maras and Acos. In contrast, the index value between the two samples from Acos was close to zero, suggesting that these samples contained the same species (Supplementary Figure S2).

These results correlate with findings reported for other saltern ponds with intermediate salinity, such as those in Santa Pola, Spain, with 13-19\% NaCl, where high abundance levels of bacteria ( 73 and $\sim 54 \%$ ) and archaeal organisms ( $27 \%$ and $\sim 46 \%$, respectively) were found $[38,44]$. The same was found when the Chao index was compared for these metagenomes [45]. In contrast, in the saltern pond located in Isla Cristina, Spain $(21 \% \mathrm{NaCl})$, Archaea were predominant ( $84 \%)$, followed by Bacteria $(\sim 16 \%)$ [38]; although the structure at the phylum level is equivalent, important differences at the genus level are attributed to particular local ecological conditions [38].

These results suggest that in environments with higher salt concentrations there is less diversity and species richness, probably because there is lower availability of nutrients and oxygen, in contrast to intermediate-salinity environments, where there is a greater availability of nutrients and oxygen. Therefore, salt concentration is an important factor that shapes the structure of the microbial community in hypersaline environments and determines its diversity and abundance.

\subsection{Bacterial and Archaeal Community Composition}

Previous studies have shown that the halophilic world is highly diverse, but this diversity is reduced with increasing salt concentrations [46]. In the case of intermediate-salinity environments, several moderately halophilic bacteria have been reported, including Halomonas, Salinivibrio, Halobacillus, Thalassobacillus, Bacillus, Salinicoccus, Idiomarina, Chromohalobacter, and Salinicoccus [7,38,47-49]. In the metagenomic samples from Maras, bacteria from the phylum Proteobacteria (38\%) were the most abundant, followed by Actinobacteria (11.58\%), Firmicutes (2.68\%), Cyanobacteria (0.40\%), Bacteroidetes $(0.40 \%)$, Deinococcus-Thermus (0.26\%), and Verrucomicrobia (0.26\%) (Figure 2).

At the species level in Maras salterns, it was interesting that the most abundant bacterium was Thiohalorhabdus denitrificans (11.51\%), which is an extremely halophilic species [50], followed by Thiohalospira halophila (0.87\%) [51]. Both of these species are chemolithoautotrophic sulfur-oxidizing bacteria which use thiosulfate as the electron donor [50,51], and neither has been reported previously in intermediate-salinity settings.

Other halophilic bacteria, such as Pseudomonas (2.15\%) and Halomonas (0.94\%), were identified in lower proportions than previously reported $[1,44,47]$. Even the main bacteria described in hypersaline systems, such as Salinibacter ruber [52,53] and Rhodovibrio salinarum [1], were found in low abundance $(\sim 0.07 \%$, each species) in our study, probably because the altitudes of these sites affect bacterial structures, as we have shown.

In addition, predominant non-halophilic bacteria found included Lawsonella clevelandensis (7.06\%), Escherichia coli (2.08\%), Clostridium difficile (1\%), Cutibacterium acnes (0.9\%), and Ralstonia solanacearum $(0.8 \%)$. The presence of non-halophilic bacteria in hypersaline environments has been previously described in the Santa Pola saltern $(19 \% \mathrm{NaCl})$, and some of these organisms have developed adaptation mechanisms, such as a strong GC bias, as has been identified in halophilic organisms as a strategy to avoid UV-induced thymidine dimer formation [44,45,54,55].

The two samples from Acos exhibited similar compositions of microorganisms: Proteobacteria corresponded to $\sim 59 \%$ of identified sequences, followed by Bacteroidetes (11\%), Balneolaeota (6\%), Firmicutes (5\%), and Actinobacteria (2\%). Both Acos metagenomes had the same composition as environments of intermediate salinity previously reported, showing a high diversity and abundance of bacteria [7,38]. Interestingly, in Acos salterns members of the Balneolaeota phylum were identified, including moderate halophiles (5-10\% $\mathrm{NaCl})$ abundant in sediments, saline soils, and marine habitats [55,56] (Figure 2b,c). 


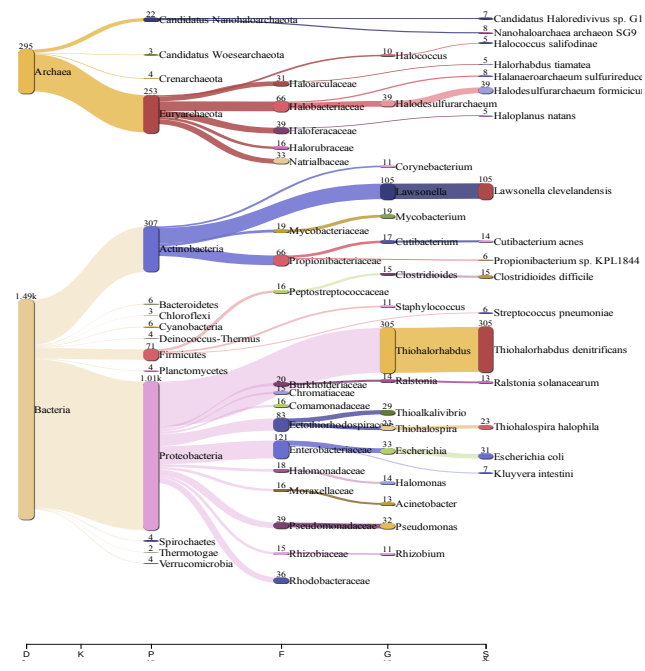

b)

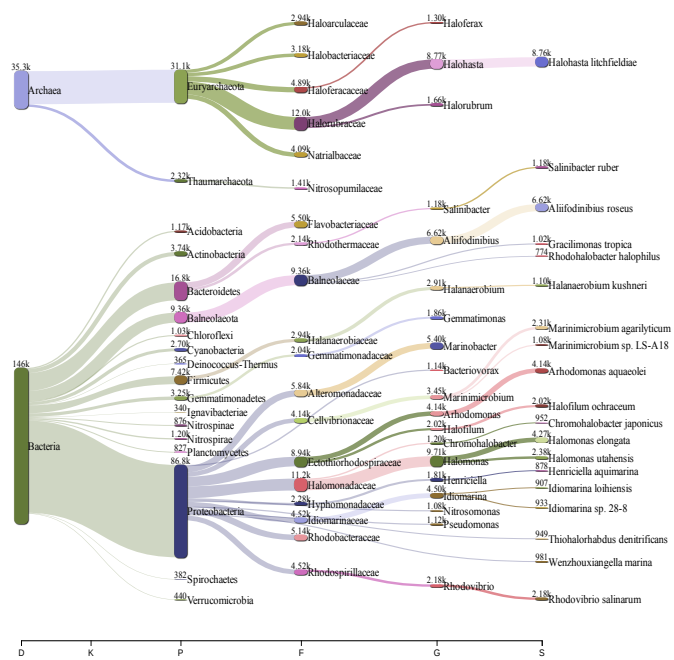

c)

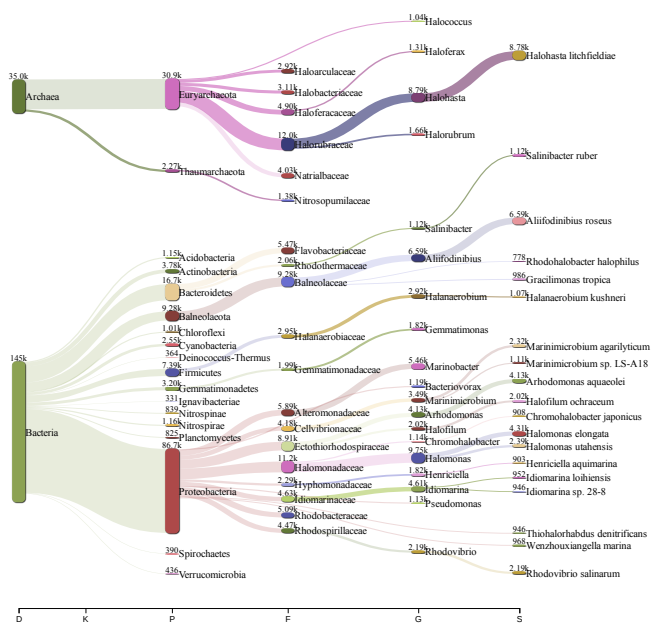

Figure 2. Taxonomic profile in hypersaline metagenomes from Cusco, Perú. (a) Maras; (b) Acos 1; (c) Acos 2. On the $x$-axis are the taxonomic levels: D, domain; P, phylum; C, class; O, order; F, family; G, genus; $\mathrm{S}$, species. Numbers correspond to the assigned contigs.

At the level of genus, Halomonas was the most abundant (8.4\%), with more than 70 different species identified in Acos; Halomonas elongata (2.8\%) was the most abundant, followed by Halomonas utehensis (1.6\%). In this regard, organisms of the Halomonas genus are aerobic heterotrophic, halo-alkaliphilic, and sulfur-oxidizing bacteria and are commonly found in intermediate-salinity, high-altitude environments [57,58]; they are also a source for the production of bioplastic polyhydroxyalkanoates [59].

In contrast, at the species level, the most abundant bacteria were Aliifodinibius roseus ( 5\%) within the phylum Balneolaeota; this species is considered moderately halophilic $(6-10 \% \mathrm{NaCl}$ for optimal growth). Also abundant were two species, Halomonas elongata (2.93\%) and Arhodomonas aquaeolei $(2.84 \%)$, an obligately halophilic bacterium with optimal growth at $15 \% \mathrm{NaCl}$; both of these species have been shown to degrade phenol [60]. To our knowledge, only a few reports have described these bacteria in a metagenome from an intermediate-salinity environment. Marinimicrobium agarilyticum, Rhodovibrio salinarum (1.50\%), Salinibacter ruber $(0.80 \%)$, and Idiomarina sp. (0.64\%) were in low abundance. Idiomarina loihiensis is a bacterium identified in environments a wide range of temperatures (from $4{ }^{\circ} \mathrm{C}$ to $46^{\circ} \mathrm{C}$ ) and salinities (from $5 \%$ to $21 \%$ ) that presents polyextremophile behavior [61].

In both the Maras and Acos sites, the low abundance of $S$. ruber is understandable, since this bacterium prefers environments with higher salinity. 
Therefore, different species of moderately halophilic bacteria were found in Acos, with Proteobacteria the most abundant. These results correlate with findings from another high-altitude saltern located in Atacama, Chile, at 2,700 $\mathrm{m}$ above sea level, where halophilic bacteria able to grow at intermediate salinity were isolated [62]. In general, the moderately halophilic bacteria are aerobic or facultative anaerobic microorganisms that belong to different genera, as part of a physiologically heterogeneous group of bacteria [47].

In intermediate-salinity salterns, such as the Peruvian hypersaline systems, the abundance of archaeal organisms is low, as found in the Maras samples, where Euryarchaeota organisms were found to be highly abundant, followed by "Candidatus Nanohaloarchaeota," and "Candidatus Woesearchaeota." In both samples from Acos, Euryarchaeota organisms were the most abundant, followed by Thaumarchaeota, Crenarchaeota, and "Candidatus Bathyarchaeota." Within the Euryarchaeota phylum, the Halobacterium family was found to be predominant, similar to findings from other salterns and salty lakes $[6,45,63,64]$.

In Maras, Halodesulfurarchaeum formicicum was the most abundant species. Halodesulfurarchaeum is a novel anaerobic genus that was discovered in a deep-sea salt-saturated anoxic environment and in sediments from hypersaline lakes [65].

In Acos, the most abundant archaeon was Halohasta litchfieldiae ( 3.5\%), a chemoorganotrophic aerobic that can grow in salt concentrations around $12-28 \%$, presenting adaptation to low temperatures [66-68] as occurs in the area of the Peruvian Andes where minimum temperatures reach between $-7^{\circ} \mathrm{C}$ and $-4.4^{\circ} \mathrm{C}$.

The taxonomic assignment analysis was also carried out with MG-RAST; the abundance of archaea was low, in accordance with the results of Kaiju. From the class Halobacteria, 14 different genera were identified, with Haloarcula genus the most predominant in the three samples (Figure 3). The presence of this genus is interesting because it has been reported to be involved in recombination processes. This process could be occurring between bacteria and archaea, among their sharing genes, for example, rhodopsin family genes which are common and have different functions such ion pumps, channels, enzymes, photosensory receptors that could favor the adaptation $[69,70]$.
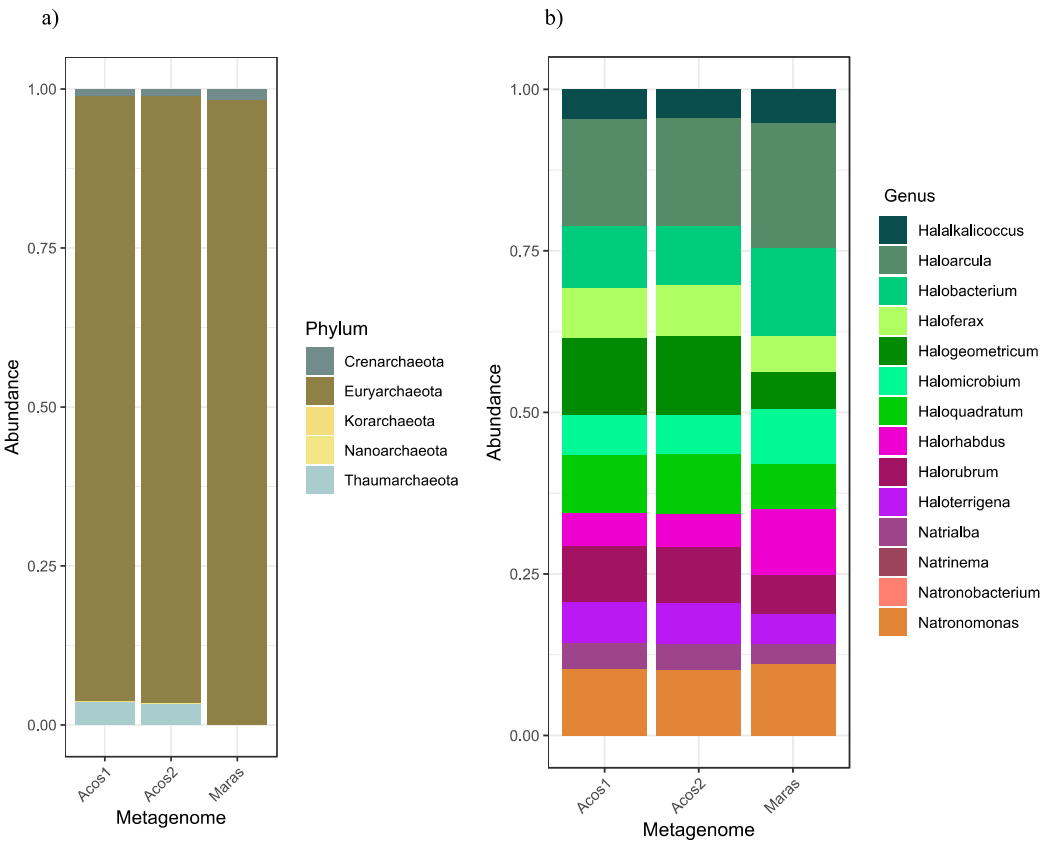

Figure 3. Taxonomic classification of archaea according to MetaGenome Rapid Annotation Subsystems Technology (MG-RAST). (a) Composition of the archaeal community at the phylum level, where Euryarchaeota prevail. (b) Diversity within the class Halobacteria. The genus Haloarcula prevails in all samples. 


\subsection{Composition of the Viral Community}

Although viruses are sources of genetic variation, as they can modify a genome's plasticity and alter the structure of populations and also biogeochemical cycles, few reports have described the structure of virus communities in hypersaline environments [71-74]. In this work, the taxonomic assignment performed with Kaiju revealed that $0.2 \%$ to $1.32 \%$ of the reads were associated with viruses (Table 1). This was probably because we did not perform a viral enrichment with our samples; however, it was possible to find viruses, because they would be included within the host cells or in the form of proviruses [75].

Because of the low percentage of detected viruses in the samples, we used Virsorter, which detects the viral signal in metagenomic datasets [18]. From the assembly of reads, we identified the viral contigs according to VirSorter, and they were subsequently classified taxonomically with MEGAN (See Materials and Methods).

The results identified the order Caudovirales, specifically, the Siphoviridae, Podoviridae, and Myoviridae families, in the samples; indeed, these families seem to be ubiquitous in marine environments [76].

Interestingly, in Maras eukaryotic viruses such as Adenovirus and Herpesvirus were identified, probably as a consequence of the composition of eukaryotic organisms in the samples, as also reported for Red Sea brines [77]. Additional double-stranded DNA (dsDNA) viruses associated with eukaryotes were also found in the Acos samples, mainly viruses from the Phycodnaviridae, Poxviridae, Mimiviridae, and Pandoravidae families (Figure 4); all of these are Megavirales, which are nucleocytoplasmic large DNA virus (NCLDVs). NCLDVs infect animals and unicellular eukaryotes [78] found in other hypersaline environments, such as the Salton Sea in the United States and Organic Lake in the Antarctic [79].

Another important group of viruses found in Acos was an unclassified archaeal dsDNA virus (Figure 4); this virus has been reported in high abundance in hypersaline environments, with spindle-shaped morphologies of Haloarchaea viruses, but this happens when salt concentration reaches saturation, where in general Archaea are predominant [12,72,80].

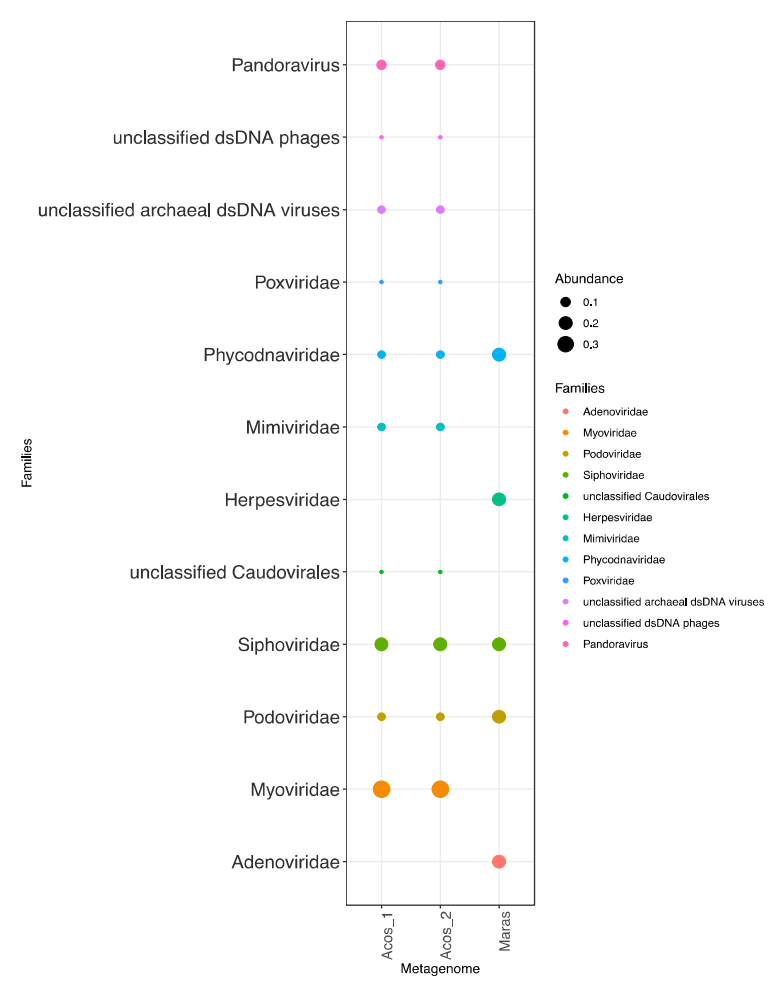

Figure 4. Compositions of the viral communities at the species level in Acos and Maras. 
In summary, we identified six virus families associated with eukaryotic cells and five families that infect Bacteria and Archaea. This last group was the most abundant, according to the microbial composition in this environment.

\subsection{Composition of Fungal Communities}

The diversity of microorganisms in intermediate-salinity systems is not restricted to prokaryotes. Approximately $2 \%$ of the reads corresponded to eukaryotes. According to the Megan classification system, two phyla of fungi were found, Ascomycota (with 85\%) and Basidiomycota (with 10\%), as has been reported for other hypersaline environments [81]. At the family level, the most abundant were Arpergillacea, followed by Sordariaceae, Sporidiobolaceae, and Chaetomiaceae (Figure 5). Aspergillus has been reported to be dominant in salterns of Slovenia, along with Cladosporium and Penicillium [82]. These filamentous fungi are ubiquitous and have been isolated with high frequency in hypersaline environments [83]. Some species in the Sordariaceae family have also been isolated from hypersaline environments. The Sporidiobolaceae family is within the Basidiomycota phylum, which has been recovered from sea water, glacier ice, and extremophile environments. Rhodotorula was recovered from hypersaline ponds in Israel [84]. The Chaetomiaceae family was recovered together with 19 inhabiting hyphomycetes fungi in soils from the hypersaline Urmia Lake [85]. Thus, a high diversity of fungi has been found in hypersaline environments, where the most abundant are melanized Aspergillus, which is a ubiquitous genus used in biotechnology applications for its production of citric acid and enzymes, and non-melanized Rhodotorula, which comprises several species that can be used in bioremediation [86].

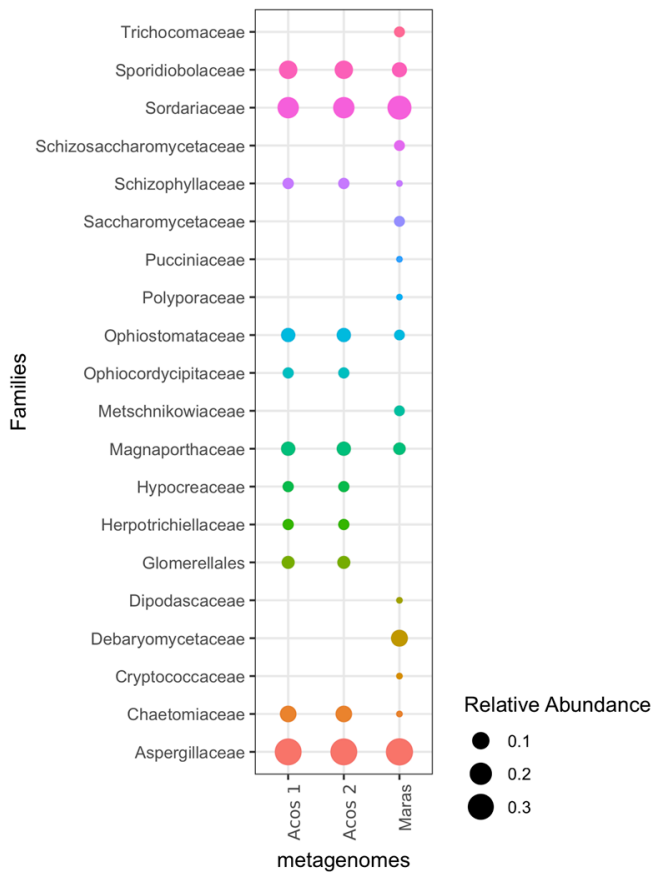

Figure 5. Diversity taxonomy of fungi. The Aspergillaceae family was the most abundant in Acos and Maras.

In summary, the results show an important diversity of fungi within the hypersaline environments; however, their functions are still unclear. 


\subsection{Genome Reconstruction}

\subsubsection{Bacterial Genome Reconstruction in A Hypersaline Environment}

One of the aims in this work was the reconstruction of complete genomes that could provide information about the main metabolic pathway associated with hypersaline metabolism. To this end, the genomes were retrieved using a fragment recruitment strategy with the reads aligned against the available reference genome [87], and their integrity was assessed with Genome Peek [88] and One codex [25] (see Materials and Methods).

According to the abundance levels found with our taxonomic assignments, the most abundant genomes were Halomonas elongate-like and Idiomarina loihiensis-like and these were retrieved from the metagenome. The complete reference genomes reported in NCBI for these bacteria were used for fragment recruitment.

First, the Halomonas elongate-like genome was reconstructed, comparing the sequences against the reference genome MAJD01000001.1. Both samples of Acos showed 93\% breadth coverage and a deep coverage of $8.3 x$ The circular chromosome of $\sim 3.7 \mathrm{Mb}$ is graphically represented in Figure 6; it has a GC content of $64 \%$, similar to Halomonas elongata isolated from Huanoquite at Peru. The average nucleotide identities (ANIs) between the reference genome (MAJD01000001.1) and the genomes from Acos 1 and Acos 2 were $98.04 \%$ and 98.02\%, respectively (Table 2).
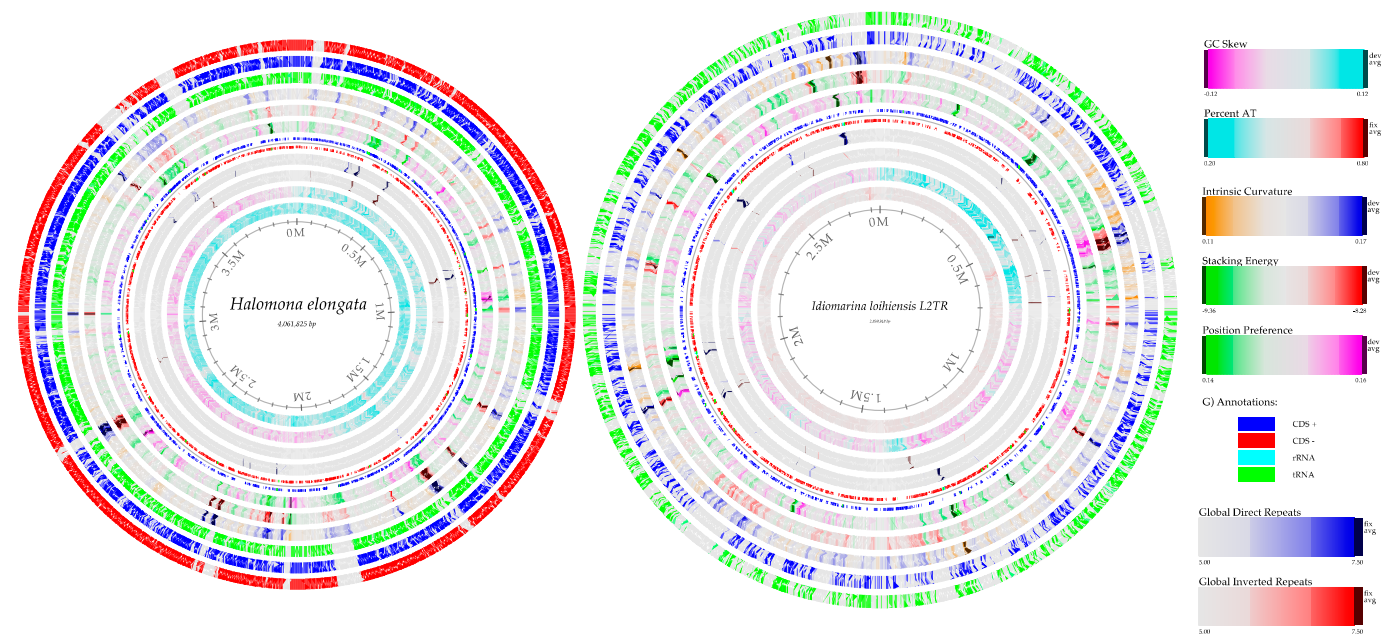

Figure 6. Draft genome comparison of Halomonas elongata and Idiomarine loihiensis. From the outside to center of the genomes of Halomonas elongate-like from Acos 2 (red) and Acos 1 (blue), the innermost rings show percent AT, GC skew, GC content, global inverted repeats, CDS-, CDS+, position preference, stacking energy, and intrinsic curvature, which are colored in a gradient, and the interpretation of the references to color is in the figure legend. The Idiomarine loihiensis-like genome from Acos 2 (green) and Acos 1 (blue) and the innermost rings show the same interpretation of genome H. elongata.

Table 2. Features of Halomonas elongata and Idiomarina loihiens is genomes with number of transfer RNA (tRNA), transfer-messenger RNA (tmRNA) and ribosomal RNA (rRNA).

\begin{tabular}{ccccc}
\hline Features & $\begin{array}{c}\text { Halomonas elongata } \\
\text { (Acos 1) }\end{array}$ & $\begin{array}{c}\text { Halomonas elongata } \\
\text { (Acos 2) }\end{array}$ & $\begin{array}{c}\text { Idiomarina loihiensis } \\
\text { (Acos 1) }\end{array}$ & $\begin{array}{c}\text { Idiomarina loihiensis } \\
\text { (Acos 2) }\end{array}$ \\
\hline Length size (bp) & $3,768,127$ & $3,763,770$ & $2,111,175$ & $2,227,077$ \\
\hline$\%$ GC & 64 & 64 & 47.2 & 47.3 \\
\hline CDS & 4564 & 4678 & 4060 & 3871 \\
\hline tRNAs & 65 & 69 & 55 & 56 \\
\hline tmRNA & 1 & 1 & 1 & 1 \\
\hline rRNAs & 12 & 12 & 12 & 13 \\
\hline
\end{tabular}


A comparison between Halomonas elongata strain HEK1 (MAJD01000001.1), H. elongata strain MH25661 (QJUB00000000.1), and the two genomes recovered from this work revealed that all strains share a core of 2,984 genes. Indeed, both genomes recovered from Acos share 916 genes, a significant number of genes in comparison to the other genomes. In addition, Idiomarina loihiensis-like, reported as a predominant genome in a saline environment, was also assembled. The coverage was $74-78 \%$ with a reference genome (I. loihiensis L2TR GCA_000008465.1), and the deep coverage was 5-6x for Acos 1 and Acos 2. Both strains share $93.0 \%$ of identity according to their ANIs. Finally, the two genomes share 2151 common genes (Supplementary Figure S3).

Interestingly, the reconstructed genomes of Halomonas elongata and Idiomarina loihiensis show different strategies for maintaining osmotic equilibrium, according to the annotation; de novo synthesis of the ectoine pathway is complete in H. elongata. Ectoine is a compatible solute of low molecular weight of aspartate metabolism, which is produced when there are increased $\mathrm{K}^{+}$-glutamate levels [89]. In contrast, in Idiomarina loihiensis, de novo synthesis of ectoine was absent; however, we identified genes encoding $\mathrm{ABC}$ transporters such as the ATP-dependent $\mathrm{Na}+$ exporter nat $A B$, in addition to other iron transporters, which promote detoxification in hypersaline environments. These findings show different adaptation strategies of bacteria in hypersaline environments.

The annotation of the genes exclusively shared between two Halomonas genomes from Acos revealed that most of them were related to nitrogen metabolism, chemical reactions, and pathways involving organic acids. Regarding the genes related to the metabolism of nitrogen, genes encoding a nitrate/nitrite sensor protein, nitrate reductase, and ammonia monooxygenase were found. This is interesting since Halomonas use nitrogen as the last acceptor of electrons even in conditions of low oxygen, as is the case in hypersaline environments [90].

In general, these Proteobacteria play an important role in the nitrogen cycle, through recycling of nitrogen by assimilation of gaseous nitrogen from the atmosphere and decomposition of organic matter, causing nitrogen to be constantly available [90].

\subsubsection{Reconstruction of Viral Genomes}

Traditional techniques limited us in obtaining viral genomes, but through metagenomics it was possible to reconstruct these genomes, allowing us to expand knowledge about the influence of viruses in this particular environment. In this regard, the viral contigs identified correspond to bacteriophages, as expected, since bacteria were more abundant in our metagenomes. In the Maras sample, a genome with $97 \%$ similarity with the lambda phage of Enterobacteria (Siphoviridae family) was found. This phage infects Escherichia coli, a non-halophilic bacterium that was abundant in this sample (Figure 7a).

In Acos samples, around 100 different contigs with viral signals were identified; because many of these could be fragments of viral sequences, different criteria were used, such as the presence of inverted terminal repeats in the case of circular genomes and similarities in size lengths with a reference genome (no more than $10 \%$ of size length) [18].

In the Acos samples, two phages of Halomonas elongata were recovered. This finding was somewhat expected, since $H$. elongata is abundant in these intermediate-salinity environments, but this is the first time that bacteriophages have been reported in this bacterium. The two recovered phages have a size length of approximately $28 \mathrm{Kbp}$, and a comparative analysis with two ФHAP-1 reference genomes revealed that they have the same pattern of synteny and a protein identity greater than $65 \%$. (Figure $7 \mathrm{~b}$ ).

The phage used for comparison was Halomonas phage $\Phi H A P-1$. This is a Hapunavirus belonging to the family Myoviridae and was isolated from Halomonas aquamarina. The GC content in $\Phi H A P-1$ is $59 \%$, which is slightly lower than other phages such as $\Phi H A P-1$, found in Acos with a $64 \%$ GC content, and similar to the GC content of the host genome (H. elongata) [91].

The $\Phi H A P-1-t y p e$ phages from Acos have 40 putative open reading frames (ORFs) with 6 genes fewer than the reference genome. Genes coding for proteins such as the RepA replication protein, the prophage repressor, the prophage antirepressor, and the protelomerase were not identified; the latter is necessary for the maintenance of the linear state of the prophage within the host genome [92]. 
In addition, inverted repeats were found at positions $28,428-28,452$ to $28,455-28,479$ with a length size of $25 \mathrm{bp}$ and an identity of $100 \%$, suggesting that the genome is in a circular form, because this kind of inverted repeated sequence is usually found in regions processed by protelomerases and originates from the release of phage with covalently closed ends. All of these findings suggest that the phage could be in their free form.

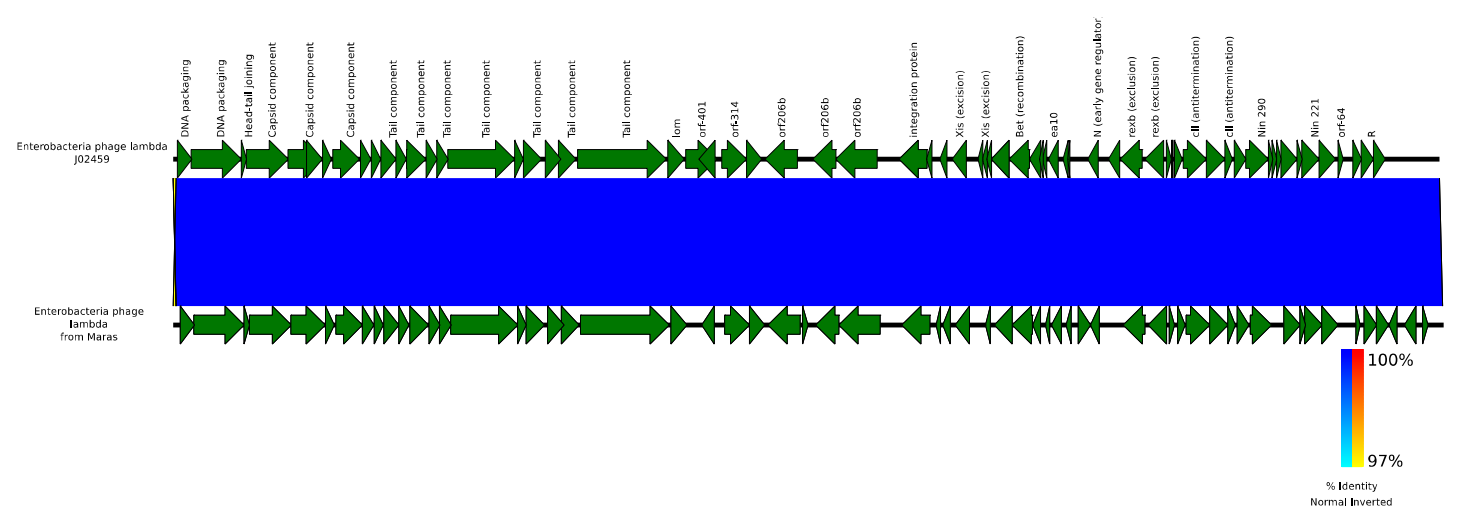

a)

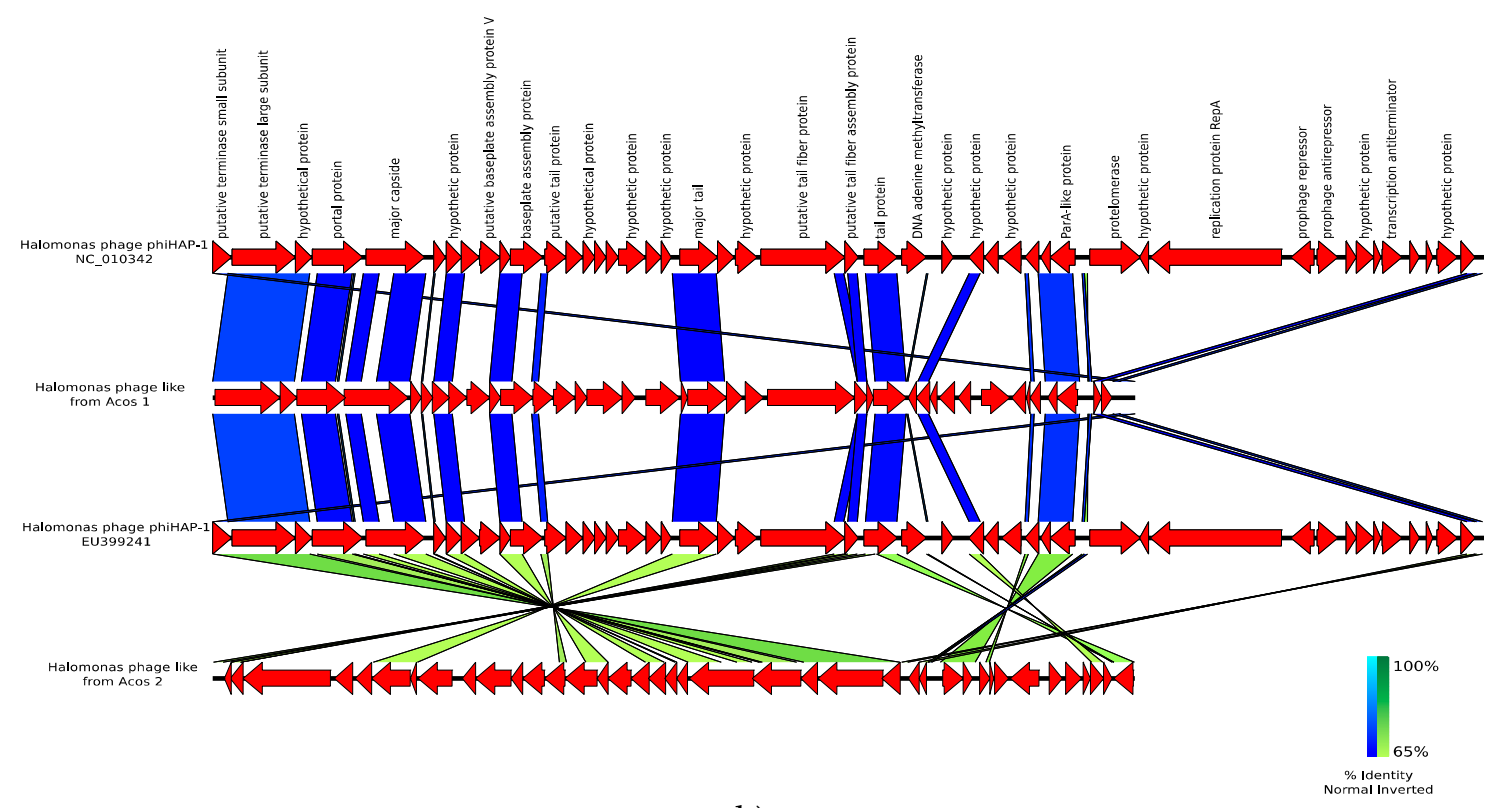

b)

Figure 7. Genomes of novel bacteriophages.

(a) Enterobacteria phage lamda-like from Maras;

(b) Halomonas phage-like (phiHAP-1) from Acos.

The rest of the viral sequences obtained in the metagenomes through BLAST analysis had very poor identity with sequences in the NCBI database, and they were used for taxonomic or functional allocation. Thus, the contigs of $>10 \mathrm{~kb}$ was clustered using the Viral RefSeq database and vConTACT2; this tool allows classification of viral sequences with protein comparisons. In Figure 8, two examples of viral assignation taxonomy are presented. In Figure 8 a viral sequence with $\sim 27 \mathrm{Kpbs}$ shares identity with proteins from Cellulophaga phage, which infects algae typically found in marine environments. In Figure 8 are four viruses with size lengths of about 11 to $30 \mathrm{Kpbs}$ that shared identities with different enterophages, showing a mosaicism as a reflection of horizontal gene transfer. In total, 27 sequences could have a taxonomic assignment as new viruses with this strategy (Supplementary Figure S4). 


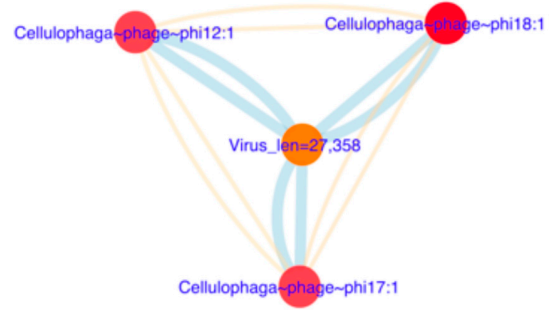

Figure 8. Protein-sharing network of genome of Cellulophaga phage. Yellow lines indicate strong similitarity, and blue lines indicate weak similarity. Thus, the virus of length 27,358 bp could be a novel virus.

\subsubsection{MAGs}

Another strategy to retrieve new genomes from metagenomic sequences with little or no identity with sequences already reported is by binning, in which genomes are assembled without a reference sequence. The binning method has the aim to classify contig sequences in a specific taxon, called metagenome-assembled genomes (MAGs). The binning methods can also describe novel species in these environments. The binning of metagenomic sequences was performed only for Acos, because at least two samples with the same origin are necessary to enrich the data. From this, a total of 42 bins were assembled in annotated draft genomes, and their ribosomal genes were extracted. However, some of this process resulted in a low degree of completeness. Therefore, we performed a phylogenetic analysis that revealed that 31 MAGs were classified within a specific domain and seven of them were closely related to the Halobacteria class (Bin 5, Bin 14, Bin 15, Bin 31, Bin 30, Bin 34, and Bin 41) (Figure 9) within the Euryarchaeota phylum, which is predominant in hypersaline environments.

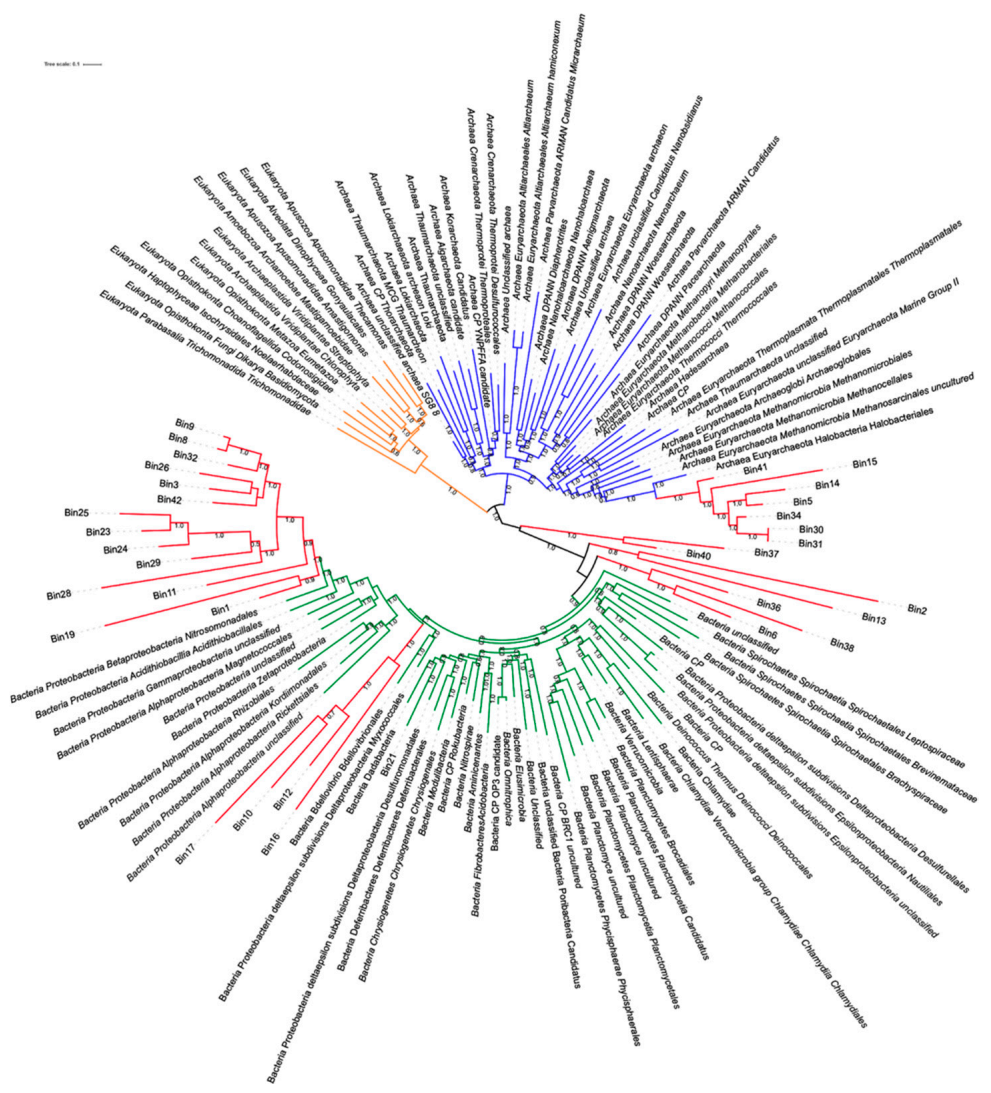

Figure 9. Phylogenetic tree, including the binned sequences associated with different taxa clades. Branches in orange correspond to Eukaryota; branches in blue correspond to Archaea; branches in green correspond to Bacteria; Branches in red correspond to bins. Bootstrap levels are noted. 
Four MAGs were closely related with Alphaproteobacteria unclassified (Bin 10, Bin 12, Bin 16, Bin 17), and 14 MAGs were closely related to Gammaproteobacteria. Indeed, most of the found bacteria corresponded to Proteobacteria, in accordance with the bacteria found in our metagenomes (Bin 1, Bin 3, Bin 8, Bin 9, Bin 11, Bin 19, Bin 23, Bin 24, Bin 25, Bin 26, Bin 28, Bin 29, Bin32, Bin 42). Therefore, in this analysis the Proteobacteria phylum prevails over the Euryarchaeota phylum in Acos samples, indicating that salinity plays an important role in the structure of the community of microorganisms that inhabits this ecosystem.

The strategies for the reconstruction of genomes, such as fragment recruitment and MaxBin, offered different results, since the first strategy is a targeted search and for the second strategy the search starts from scratch in obtaining draft genomes. Another important difference is that the latter assemblies, coming from more than one metagenome, could build chimeric genomes. However, with the two strategies, genomes of Gammaproteobacteria similar to Halomonas could be reconstructed.

\subsection{Functional Community Composition}

The strategies that halophilic organisms use to survive in hypersaline environments are diverse and include thickening of the cell wall, increase in pigmentation, production of compatible solutes, solute transport mechanisms, and production of antibiotic proteins to limit the growth of other populations [93]. Therefore, we analyzed the functional composition of microorganisms in intermediate-salinity environments in order to determine how these mechanisms are potentially used by microorganisms in these environments.

Thus, the contigs from hypersaline metagenomes were annotated using SEED subsystems, and these results revealed that $11-13 \%$ of coding sequences from Acos and $14 \%$ of those from Maras were related to metabolism of carbohydrates (central carbohydrate metabolism, synthesis of monosaccharides and polysaccharides) (Figure 10).

The genes classified into the category of amino acids and derivatives functions were present in $\sim 8 \%$ to $12 \%$ in Acos and $\sim 11 \%$ in Maras. Overall, in the three metagenomes the synthesis of lysine, threonine, methionine, and cysteine were the more abundant categories. This correlated with the fact that in some halophilic bacteria there is a preferential use of codons to encode these amino acids [94]. In this regard, most of these amino acids are hydrophobic, found on the inside of proteins, especially in hypersaline environments, which strengthen the hydrophobic interactions [92].

Other categories overrepresented, with $\sim 6.7 \%$ to $\sim 9.77 \%$ abundance in samples, were respiration, functions related to donating/accepting electrons, and ATP synthases. All of these participate in the transfer of electrons to obtain energy.

Interestingly, the category related to pigment functions was found in $8 \%$ to $10 \%$ Acos sequences and $7 \%$ of Maras sequences. The class Halobacteriaceae is mainly responsible for $\alpha$-bacterioruberin pigment, a pink-red product in hypersaline environments. In addition, Salinibacter ruber is responsible for producing salinixanthin carotenoid, a C-40 acyl glycoside carotenoid that also contributes to the coloration of salterns. This bacteria and these pigments are important in hypersaline environments as they reduce the UV irradiation that damages DNA, which tends to be high in these saline environments [9].

The category of membrane transport was present in $\sim 3 \%$ to $\sim 5 \%$ abundance; in particular, the membrane proteins in Gram-negative bacteria were more abundant than in Gram-positive bacteria, including the YrbG Na${ }^{+} / \mathrm{Ca}^{2+}$ cation antiporter, a very important protein in this kind of saline environment. This system has been reported in Haloarchaea, which have a wide variety of ion transporters, to have a role in regulating fluctuating salinity levels and avoiding osmotic shock [95]. In other salterns with intermediate salinity, such as Santa Pola $(13 \% \mathrm{NaCl})$, genes related to this function have been reported to be overrepresented [45].

The function of resistance to antibiotics and toxic compounds was also found to be abundant in these metagenomes, including pathways involved in sulfur heavy metal cycling, cobalt-zinc-cadmium resistance, and also copper homeostasis and resistance to arsenic. Since heavy metals such as arsenic 
do not have biological roles, low concentrations are toxic to the cell, and therefore microorganisms have mechanisms for reduction. Many Archaea have different heavy metal transporters [96].

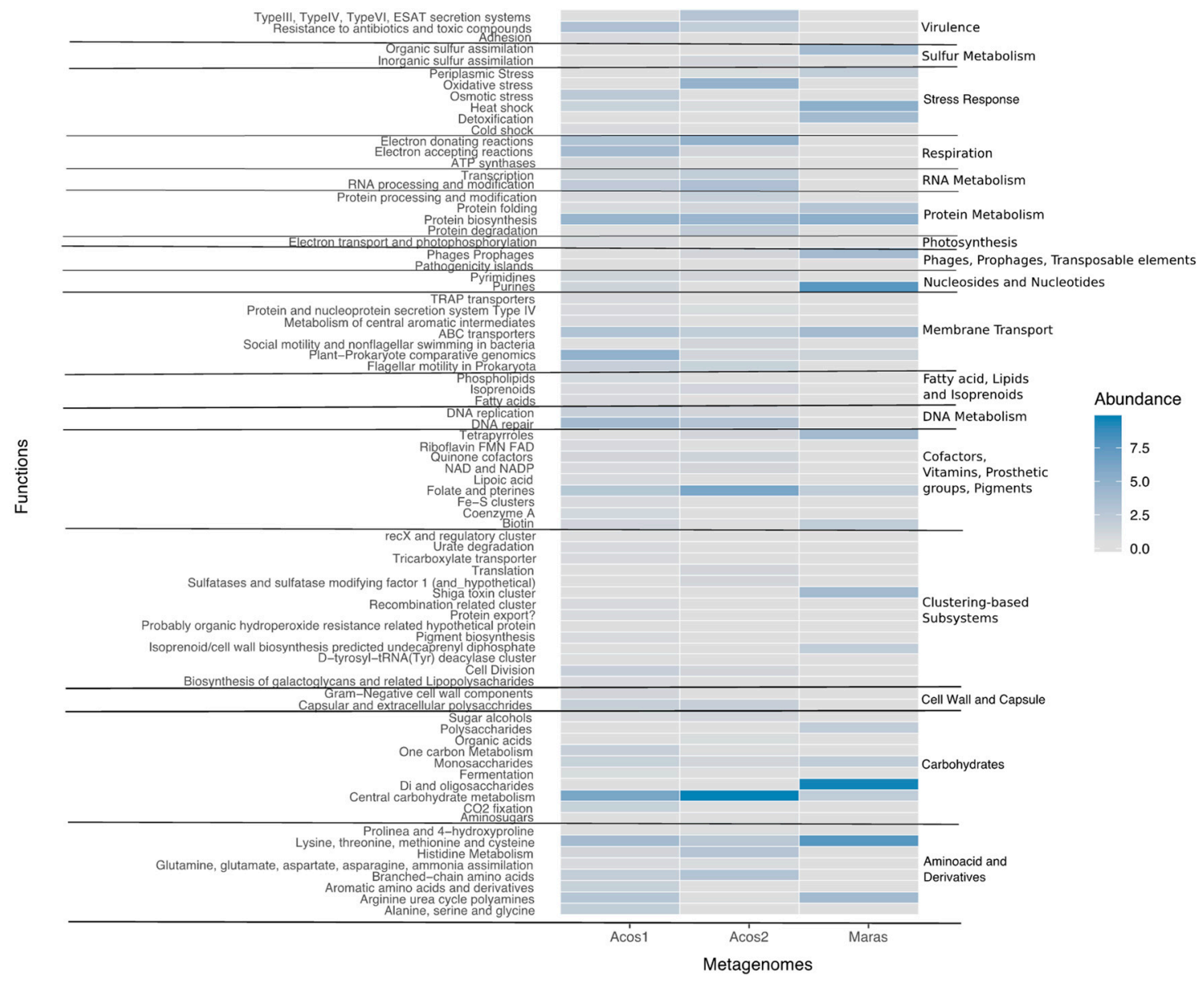

Figure 10. Heatmap of the relative abundance of proteins based on SEED classifications.

In addition, the stress category was more abundant in Maras $(\sim 14 \%)$ than in Acos $(\sim 6 \%)$. This category includes predominant functions such as oxidative stress, osmotic stress, heat stress, detoxification, cold shock, and periplasmic stress. These types of functions were prevalent in Maras, and although the concentration of salt was higher in Maras than in Acos, a greater presence of non-halophilic organisms was identified in Maras. It is well known that organisms growing in high concentrations of salt accumulate stress molecules, such as reactive oxygen species, and the organisms must therefore have mechanisms for their detoxification [97].

In the same way, samples from Acos presented abundant oxidative stress functions. Reactive oxygen species in hypersaline environments are common, thus organisms in these environments have detoxification mechanisms. In particular, in microaerophilic and anaerobic metagenomes, oxygen-detoxifying enzymes have been identified, such as superoxide dismutases, catalases, peroxidases, and glutathione peroxidase [98]. In the Acos metagenome, we identified enzymes involved in the response to oxidative stress, such as 5-oxoprolinase, and enzymes responsible for maintaining the reducing environment, such as glutathione reductase, glutathione hydrolase (involved in reduction of glutathione disulfide), and hydroperoxide resistance (responsible for detoxification of organic hydroperoxides).

Since the microorganisms are under oxidative stress, it is common to identify redundant enzymes responsible for DNA repair [99]. However, reactive oxygen species are not the only compounds that modify the genetic material; other agents that produce data in the genetic material include UV light 
exposure and desiccation, and so, as expected, the functions of DNA synthesis and DNA repair are the most represented in proteins found in the Acos samples.

According to our analysis with MG-RAST, detoxification enzymes were identified in Archaea, within the classification "housecleaning nucleoside triphosphate pyrophosphatases"; all of these belonged to class Nudix hydrolases, including nucleoside 5-triphosphatase and 5-nucleotidase SurE. In Bacteria, these enzymes were found in high abundance, as was the dimeric dUTPase enzyme. Interestingly, viruses also possess detoxification enzymes of this category, in particular the enzyme deoxyuridine $5^{\prime}$-triphosphate nucleotidohydrolase, that decreases the intracellular concentration of dUTP so that uracil cannot be incorporated into viral progeny DNA.

All of the above enzymes are responsible for the elimination of damaged nucleotides caused by reactive oxygen species. For viruses, the incorporation of damaged nucleotides in nucleic acids is detrimental to replication of viral progeny. In this way, the virus could contribute to the adaptation of the host to its environment.

Regarding DNA repair, we found bacterial systems that contribute to this function, among which were base excision repair (BER), repair of DNA double-strand breaks (DSBs) (RecBCD pathway and RecFOR pathway), nucleotide excision repair (NER), and DNA mismatch repair (MutL-MutS system). However, the mechanisms of nucleotide excision repair (NER) and DNA mismatch repair (MutL-MutS system) were more abundant in Bacteria. The function related to nucleotide excision repair has also been reported to be overrepresented in hypersaline environments [100].

In addition, we identified eight proteins related to DNA DSB repair in the annotations for viral sequences; this is one of the most common damaging events [101]. However, bacteriophages and some NCLDV possess homologous proteins, such as Rad50/SbcC, which is probably involved in the processing of dsDNA ends for processing during recombination [102]. These proteins were also identified in circular genomes of bacteriophages, such as Vibrio parahaemolyticus bacteriophage [103], which could indicate that these proteins are also propagated in this type of virus and could have implications in the repair of genetic material in stress environments. Other genes for methyltransferase enzymes, which are ubiquitous in the prokaryotic world and are associated with host protection of DNA damage, were also identified in our viral sequences.

Other functionally important genes found in viral sequences were auxiliary metabolic genes (AMGs) originally from the genome host. The AMGs found were ribonucleotide reductases and $p h o H$, among others. The ribonucleotide reductases are associated with lytic rather than temperate viruses, and the $\mathrm{phoH}$ gene plays a role in the transport of phosphate in conditions of starvation. Synechococcus and Prochlorococcus (cyanophages) carry AMGs; however, in this study we found these families were in low abundance, as they are predominantly found in marine environments, so it correlates with the abundance of these families reported above [104].

\subsection{Metabolic Pathway Involved in Biogeochemical Cycles}

In order to evaluate the contribution of different metabolic pathways in the biogeochemical cycles associated the metagenomes, MEBS software was used to analyze the three samples. From this analysis, only two complete pathways of the carbon cycle were identified (Figure 11), while the nitrogen and sulfur cycles in the samples were more highly represented (Figure 11). In the case of nitrogen, the pathways of denitrification and the reduction of nitrate by assimilation were found to be more prevalent, since that nitrite is generally produced under anoxic conditions such as in hypersaline environments [6]. On the other hand, the reduction of dissimilatory nitrate (nitrite-ammonia) involving the proteins encoded by the genes $\operatorname{nir} B, \operatorname{nir} D, n r f A$, and $n r f H$ is generally more highly expressed in Proteobacteria, Bacteroidetes, Euryarchaeota, and Verrucomicrobia [90]. Those were found as complete in our metagenomes, which correlates with the great abundance of Proteobacteria in the metagenomes. 


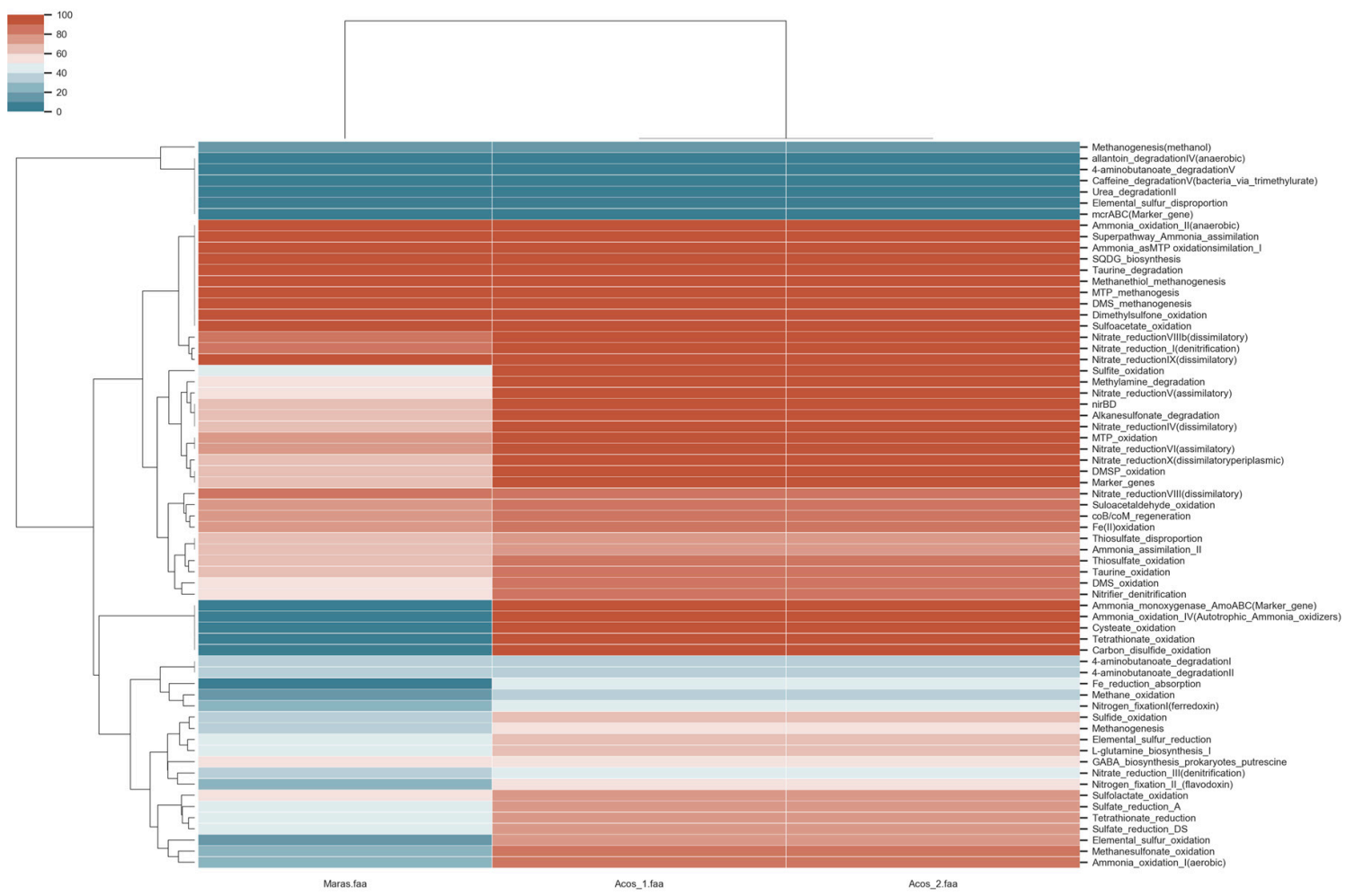

Figure 11. Completeness pathways of biogeochemical cycles. Mainly the pathways of nitrogen and sulfur cycles are complete within the hypersaline samples.

Because oxygen is limited, denitrification (nitrate-nitrite) is another pathway that contributes to the nitrogen cycle. In addition, species in the environment use nitrogen as a source of growth $[105,106]$. These pathways were also found as complete in the metagenomes of Acos, which indicates the importance of nitrogen in hypersaline environments. In this pathway, the proteins encoded by the genes narGHIJ, napAB, nirKS, norBC, and nosZ are included; these genes are expressed by Bacteroidetes, Euryarchaeota, and Proteobacteria. In addition, the narL gene in the virus compensates for the metabolic pathways of the microorganisms for nitrogen metabolism [90,107]. Finally, in the Maras sample, partially complete denitrification pathways were found (a $40-60 \%$ of representation), indicating that microorganisms can contribute to the reduction of nitrate and nitrite for the production of $\mathrm{N}_{2}$.

Some organisms, such as Proteobacteria and Thaumarchaeota, are responsible for producing nitrate by nitrification at high salt concentrations $[93,108]$, as well as the route of nitrogen fixation; however, they were partially complete, despite nitrite being an important energy source (Figure 11). In this regard, nitrite is not the only source of energy in this environment, since many Archaea and some bacteria use sulfur compounds as donors or electron acceptors for energy production [109]. In this case, the pathways related to sulfite oxidation, oxidation of sulfur DMS, and oxidation of dimethylsulfoniopropionate (DMSP) were found to be complete. Mainly, DMSP has been reported in abundance, which indicates that DMSP is an important source of carbon and energy [110]. Therefore, Bacteria and Archaea contribute to the oxidation of DMSP as an energy source, at different proportions.

\section{Conclusions}

In this study, we present a snapshot of microbial and functional diversity of two intermediate hypersaline environments in the Peruvian Andes, based on a metagenomics shotgun approach. The intermediate salinity environments show a great diversity and abundance of bacteria, more so than the archaea in the samples. At the level of phylum, Proteobacteria are the most abundant and predominated over other bacteria and archaea. However, the Balneolaeota phylum was found only in 
Acos in great abundance, but was not diverse. In addition, we reconstructed the draft genomes of $H$. elongata and I. loihiensis, which have different mechanisms of adaptation to hypersaline environments, via de novo synthesis of ectoine and nat $A B$ transporters, respectively. Also, we obtained whole genomes from bacteriophages. Functional analysis indicated that microorganism in hypersaline environments contribute to the biogeochemical cycles involving carbon and nitrogen as the source of energy. We also found genes related to oxidative stress and DNA repair. Interestingly, viruses also had such repair protein genes, which are otherwise exclusive to eukaryotes and bacteria. This study contributes to the current knowledge of intermediate-salinity environments at high altitudes.

Supplementary Materials: The following are available online at http:/www.mdpi.com/2073-4425/10/11/891/s1, Figure S1: Rarefaction curves based at level species diversity, Figure S2: Dendrogram of all samples. Analysis of beta-diversity was carried out at species level using hclust and Bray-Curtis dissimilarity, Figure S3: Pangenome of draft genome (a) Halomonas elongata (b) Idiomarina loihienis, Figure S4: Protein-sharing viral network of virus from samples of Acos, Table S1: Indexes of diversity.

Author Contributions: Conceptualization, H.G.C.-S., M.A.Q.-R., and S.D.-R.; Data curation, R.A.B.-G.; Formal analysis, H.G.C.-S. and E.P.-R.; Funding acquisition, M.A.Q.-R. and S.D.-R.; Investigation, H.G.C.-S. and S.D.-R.; Methodology, H.G.C.-S., P.E., P.R., A.L.-T., J.L.S., R.A.B.-G., G.L.-U., E.P.-R., and M.A.Q.-R.; Resources, I.V., E.P.-R., M.A.Q.-R., and S.D.-R.; Software, H.G.C.-S., E.P.-R., and S.D.-R.; Supervision, S.D.-R.; Writing-original draft, H.G.C.-S., R.A.B.-G., S.T.-S., and E.P.-R.; Writing-review and editing, M.A.Q.-R. and S.D.-R.

Funding: This research was partially funded by contract number 227-2015-FONDECYT approved by resolution CU-005-2016_UNSAAC and contract number 23-2018-UNSAAC approved by resolution R-392-2018-UNSAAC to M.A.Q.R.; and by the Dirección General de Asuntos del Personal Académico, Universidad Nacional Autónoma de México, PAPIIT IN-201117 to E.P.R. H.G.C.S. is a scholarship recipient of Mexican Consejo Nacional de Ciencia y Tecnología (CONACYT Number 227229) program fellowship.

Acknowledgments: We thank the Unidad de Secuenciación Masiva y Bioinformática of Instituto de Biotecnología-UNAM for giving us access to its computer cluster and the Centro de Investigación en Dinámica Celular for giving us access to its server.

Conflicts of Interest: The authors declare that the research was conducted in the absence of any commercial or financial relationships that could be construed as a potential conflict of interest.

\section{References}

1. Maturrano, L.; Santos, F.; Rosselló-Mora, R.; Antón, J. Microbial diversity in Maras salterns, a hypersaline environment in the Peruvian Andes. Appl. Environ. Microbiol. 2006, 72, 3887-3895. [CrossRef] [PubMed]

2. Hernández, L.M. Caracterización de la Microbiota de las Salinas de Maras, un Ambiente Hipersalino de los Andes de Perú. Ph.D. Thesis, Universitat d'Alacant-Universidad de Alicante, Alicante, Spain, 2004.

3. Grant, W.D. Life at low water activity. Philos. Trans. R. Soc. B Biol. Sci. 2004, 359, 1249-1267. [CrossRef] [PubMed]

4. Demergasso, C.; Casamayor, E.O.; Chong, G.; Galleguillos, P.; Escudero, L.; Pedrós-Alió, C. Distribution of prokaryotic genetic diversity in athalassohaline lakes of the Atacama Desert, Northern Chile. FEMS Microbiol. Ecol. 2004, 48, 57-69. [CrossRef] [PubMed]

5. Ventosa, A.; de la Haba, R.R.; Sánchez-Porro, C.; Papke, R.T. Microbial diversity of hypersaline environments: A metagenomic approach. Curr. Opin. Microbiol. 2015, 25, 80-87. [CrossRef] [PubMed]

6. Naghoni, A.; Emtiazi, G.; Amoozegar, M.A.; Cretoiu, M.S.; Stal, L.J.; Etemadifar, Z.; Shahzadeh Fazeli, S.A.; Bolhuis, H. Microbial diversity in the hypersaline Lake Meyghan, Iran. Sci. Rep. 2017, 7, 11522. [CrossRef] [PubMed]

7. Fernández, A.B.; Vera-Gargallo, B.; Sánchez-Porro, C.; Ghai, R.; Papke, R.T.; Rodriguez-Valera, F.; Ventosa, A. Comparison of prokaryotic community structure from Mediterranean and Atlantic saltern concentrator ponds by a metagenomic approach. Front. Microbiol. 2014, 5. [CrossRef] [PubMed]

8. Quillaguamán, J.; Hashim, S.; Bento, F.; Mattiasson, B.; Hatti-Kaul, R. Poly( $\beta$-hydroxybutyrate) production by a moderate halophile, Halomonas boliviensis LC1 using starch hydrolysate as substrate. J. Appl. Microbiol. 2005, 99, 151-157. [CrossRef]

9. Oren, A. Saltern evaporation ponds as model systems for the study of primary production processes under hypersaline conditions. Aquat. Microb. Ecol. 2009, 56, 193-204. [CrossRef] 
10. Ventosa, A.; Fernández, A.B.; León, M.J.; Sánchez-Porro, C.; Rodriguez-Valera, F. The Santa Pola saltern as a model for studying the microbiota of hypersaline environments. Extrem. Life Extreme Cond. 2014, 18, 811-824. [CrossRef]

11. Haferburg, G.; Gröning, J.A.D.; Schmidt, N.; Kummer, N.-A.; Erquicia, J.C.; Schlömann, M. Microbial diversity of the hypersaline and lithium-rich Salar de Uyuni, Bolivia. Microbiol. Res. 2017, 199, $19-28$. [CrossRef]

12. Emerson, J.B.; Thomas, B.C.; Andrade, K.; Allen, E.E.; Heidelberg, K.B.; Banfield, J.F. Dynamic Viral Populations in Hypersaline Systems as Revealed by Metagenomic Assembly. Appl. Environ. Microbiol. 2012, 78, 6309-6320.11. [CrossRef] [PubMed]

13. Sarwar, K.; Azam, I.; Tahir, I. Biology and Applications of Halophilic Bacteria and Archea: A Review. Electron. J. Biol. 2015, 11, 98-103.

14. Bioinformatics, B. FastQC: A Quality Control. Tool for High. Throughput Sequence Data; Babraham Institute: Cambridge, UK, 2011.

15. Fu, L.; Niu, B.; Zhu, Z.; Wu, S.; Li, W. CD-HIT: Accelerated for clustering the next-generation sequencing data. Bioinformatics 2012, 28, 3150-3152. [CrossRef] [PubMed]

16. Li, D.; Liu, C.-M.; Luo, R.; Sadakane, K.; Lam, T.-W. MEGAHIT: An ultra-fast single-node solution for large and complex metagenomics assembly via succinct de Bruijn graph. Bioinformatics 2015, 31, 1674-1676. [CrossRef] [PubMed]

17. Glass, E.M.; Wilkening, J.; Wilke, A.; Antonopoulos, D.; Meyer, F. Using the metagenomics RAST server (MG-RAST) for analyzing shotgun metagenomes. Cold Spring Harb. Protoc. 2010, 2010, Pdb.prot5368. [CrossRef]

18. Roux, S.; Enault, F.; Hurwitz, B.L.; Sullivan, M.B. VirSorter: Mining viral signal from microbial genomic data. PeerJ 2015, 3, e985. [CrossRef]

19. Huson, D.H.; Beier, S.; Flade, I.; Górska, A.; El-Hadidi, M.; Mitra, S.; Ruscheweyh, H.-J.; Tappu, R. MEGAN Community Edition-Interactive Exploration and Analysis of Large-Scale Microbiome Sequencing Data. PLoS Comput. Biol. 2016, 12, e1004957. [CrossRef] [PubMed]

20. McMurdie, P.J.; Holmes, S. phyloseq: An R package for reproducible interactive analysis and graphics of microbiome census data. PLoS ONE 2013, 8, e61217. [CrossRef]

21. R Development Core Team. R: A Language and Environment for Statistical Computing. R Foundation for Statistical Computing, Vienna. 2011. Available online: http://www.R-project.org (accessed on 30 September 2019).

22. Langmead, B.; Salzberg, S.L. Fast gapped-read alignment with Bowtie 2. Nat. Methods 2012, 9, 357-359. [CrossRef]

23. Bushnell, B. BBMap Short-Read Aligner, and Other Bioinformatics Tools; University of California: Berkeley, CA, USA, 2015.

24. Golosova, O.; Henderson, R.; Vaskin, Y.; Gabrielian, A.; Grekhov, G.; Nagarajan, V.; Oler, A.J.; Quiñones, M.; Hurt, D.; Fursov, M.; et al. Unipro UGENE NGS pipelines and components for variant calling, RNA-seq and ChIP-seq data analyses. PeerJ 2014, 2, e644. [CrossRef]

25. Minot, S.S.; Krumm, N.; Greenfield, N.B. One Codex: A Sensitive and Accurate Data Platform for Genomic Microbial Identification. Bioinformatics 2015. [CrossRef]

26. Seemann, T. Prokka: Rapid prokaryotic genome annotation. Bioinformatics 2014, 30, 2068-2069. [CrossRef] [PubMed]

27. Zhou, Y.; Liang, Y.; Lynch, K.H.; Dennis, J.J.; Wishart, D.S. PHAST: A Fast Phage Search Tool. Nucleic Acids Res. 2011, 39, W347-W352. [CrossRef] [PubMed]

28. Bolduc, B.; Jang, H.B.; Doulcier, G.; You, Z.-Q.; Roux, S.; Sullivan, M.B. vConTACT: An iVirus tool to classify double-stranded DNA viruses that infect Archaea and Bacteria. PeerJ 2017, 5, e3243. [CrossRef] [PubMed]

29. Wu, Y.-W.; Tang, Y.-H.; Tringe, S.G.; Simmons, B.A.; Singer, S.W. MaxBin: An automated binning method to recover individual genomes from metagenomes using an expectation-maximization algorithm. Microbiome 2014, 2, 26. [CrossRef]

30. Hug, L.A.; Baker, B.J.; Anantharaman, K.; Brown, C.T.; Probst, A.J.; Castelle, C.J.; Butterfield, C.N.; Hernsdorf, A.W.; Amano, Y.; Ise, K.; et al. A new view of the tree of life. Nat. Microbiol 2016, 1, 16048. [CrossRef] 
31. Katoh, K.; Standley, D.M. MAFFT Multiple Sequence Alignment Software Version 7: Improvements in Performance and Usability. Mol. Biol. Evol. 2013, 30, 772-780. [CrossRef]

32. Price, M.N.; Dehal, P.S.; Arkin, A.P. FastTree: Computing Large Minimum Evolution Trees with Profiles instead of a Distance Matrix. Mol. Biol. Evol. 2009, 26, 1641-1650. [CrossRef]

33. Letunic, I.; Bork, P. Interactive tree of life (iTOL) v3: An online tool for the display and annotation of phylogenetic and other trees. Nucleic Acids Res. 2016, 44, W242-W245. [CrossRef]

34. Hyatt, D.; Chen, G.-L.; LoCascio, P.F.; Land, M.L.; Larimer, F.W.; Hauser, L.J. Prodigal: Prokaryotic gene recognition and translation initiation site identification. BMC Bioinform. 2010, 11, 119. [CrossRef]

35. Silva, G.G.Z.; Green, K.T.; Dutilh, B.E.; Edwards, R.A. SUPER-FOCUS: A tool for agile functional analysis of shotgun metagenomic data. Bioinformatics 2016, 32, 354-361. [CrossRef] [PubMed]

36. Wickham, H. ggplot2: Elegant Graphics for Data Analysis; Springer: New York, NY, USA, 2016.

37. De Anda, V.; Zapata-Peñasco, I.; Poot-Hernandez, A.C.; Eguiarte, L.E.; Contreras-Moreira, B.; Souza, V. MEBS, a software platform to evaluate large (meta)genomic collections according to their metabolic machinery: Unraveling the sulfur cycle. GigaScience 2017, 6. [CrossRef] [PubMed]

38. Fernandez, A.B.; Ghai, R.; Martin-Cuadrado, A.B.; Sanchez-Porro, C.; Rodriguez-Valera, F.; Ventosa, A. Metagenome Sequencing of Prokaryotic Microbiota from Two Hypersaline Ponds of a Marine Saltern in Santa Pola, Spain. Genome Announc. 2013, 1. [CrossRef]

39. Fernández, A.B.; Ghai, R.; Martin-Cuadrado, A.-B.; Sánchez-Porro, C.; Rodriguez-Valera, F.; Ventosa, A. Prokaryotic taxonomic and metabolic diversity of an intermediate salinity hypersaline habitat assessed by metagenomics. FEMS Microbiol. Ecol. 2014, 88, 623-635. [CrossRef] [PubMed]

40. Wang, J.; Yang, D.; Zhang, Y.; Shen, J.; van der Gast, C.; Hahn, M.W.; Wu, Q. Do Patterns of Bacterial Diversity along Salinity Gradients Differ from Those Observed for Macroorganisms? PLoS ONE 2011, 6, e27597. [CrossRef] [PubMed]

41. Fierer, N.; Jackson, R.B. The diversity and biogeography of soil bacterial communities. Proc. Natl. Acad. Sci. USA 2006, 103, 626-631. [CrossRef] [PubMed]

42. Pagaling, E.; Wang, H.; Venables, M.; Wallace, A.; Grant, W.D.; Cowan, D.A.; Jones, B.E.; Ma, Y.; Ventosa, A.; Heaphy, S. Microbial Biogeography of Six Salt Lakes in Inner Mongolia, China, and a Salt Lake in Argentina. Appl. Environ. Microbiol. 2009, 75, 5750-5760. [CrossRef]

43. Mora-Ruiz, M.D.; Cifuentes, A.; Font-Verdera, F.; Pérez-Fernández, C.; Farias, M.E.; González, B.; Orfila, A.; Rosselló-Móra, B. Biogeographical patterns of bacterial and archaeal communities from distant hypersaline environments. Syst. Appl. Microbiol. 2018, 41, 139-150. [CrossRef]

44. Ghai, R.; Pašić, L.; Fernández, A.B.; Martin-Cuadrado, A.-B.; Mizuno, C.M.; McMahon, K.D.; Papke, R.T.; Stepanauskas, R.; Rodriguez-Brito, B.; Rohwer, F.; et al. New Abundant Microbial Groups in Aquatic Hypersaline Environments. Sci. Rep. 2011, 1, 135. [CrossRef]

45. Vera-Gargallo, B.; Ventosa, A. Metagenomic Insights into the Phylogenetic and Metabolic Diversity of the Prokaryotic Community Dwelling in Hypersaline Soils from the Odiel Saltmarshes (SW Spain). Genes 2018, 9, 152. [CrossRef]

46. Ma, Y.; Galinski, E.A.; Grant, W.D.; Oren, A.; Ventosa, A. Halophiles 2010: Life in Saline Environments. Appl. Environ. Microbiol. 2010, 76, 6971-6981. [CrossRef] [PubMed]

47. Ventosa, A.; Nieto, J.J.; Oren, A. Biology of Moderately Halophilic Aerobic Bacteria. Microbiol. Mol. Biol. Rev. 1998, 62, 504-544. [PubMed]

48. Arahal, D.R.; García, M.T.; Vargas, C.; Cánovas, D.; Nieto, J.J.; Ventosa, A. Chromohalobacter salexigens sp. nov., a moderately halophilic species that includes Halomonas elongata DSM 3043 and ATCC 33174. Int. J. Syst. Evol. Microbiol. 2001, 51, 1457-1462. [CrossRef] [PubMed]

49. Babavalian, H.; Amoozegar, M.A.; Pourbabaee, A.A.; Moghaddam, M.M.; Shakeri, F. Isolation and identification of moderately halophilic bacteria producing hydrolytic enzymes from the largest hypersaline playa in Iran. Microbiology 2013, 82, 466-474. [CrossRef]

50. Sorokin, D.Y.; Tourova, T.P.; Galinski, E.A.; Muyzer, G.; Kuenen, J.G. Thiohalorhabdus denitrificans gen. nov., sp. nov., an extremely halophilic, sulfur-oxidizing, deep-lineage gammaproteobacterium from hypersaline habitats. Int. J. Syst. Evol. Microbiol. 2008, 58, 2890-2897. [CrossRef]

51. Sorokin, D.Y.; Tourova, T.P.; Muyzer, G.; Kuenen, G.J. Thiohalospira halophila gen. nov., sp. nov. and Thiohalospira alkaliphila sp. nov., novel obligately chemolithoautotrophic, halophilic, sulfur-oxidizing gammaproteobacteria from hypersaline habitats. Int. J. Syst. Evol. Microbiol. 2008, 58, 1685-1692. [CrossRef] 
52. Oren, A. Life at high salt concentrations, intracellular $\mathrm{KCl}$ concentrations, and acidic proteomes. Front. Microbiol. 2013, 4. [CrossRef]

53. González-Torres, P.; Gabaldón, T. Genome Variation in the Model Halophilic Bacterium Salinibacter ruber. Front. Microbiol. 2018, 9. [CrossRef]

54. Kennedy, S.P.; Ng, W.V.; Salzberg, S.L.; Hood, L.; DasSarma, S. Understanding the Adaptation of Halobacterium Species NRC-1 to Its Extreme Environment through Computational Analysis of Its Genome Sequence. Genome Res. 2001, 11, 1641-1650. [CrossRef]

55. Paul, S.; Bag, S.K.; Das, S.; Harvill, E.T.; Dutta, C. Molecular signature of hypersaline adaptation: Insights from genome and proteome composition of halophilic prokaryotes. Genome Biol. 2008, 9, R70. [CrossRef]

56. Vera Gargallo, B.; Roy Chowdhury, T.; Brown, J.; Fansler, S.J.; Durán Viseras, A.; Sánchez-Porro Álvarez, C.; Bailey, V.L.; Jansson, J.K.; Ventosa, A. Spatial distribution of prokaryotic communities in hypersaline soils. Sci. Rep. 2019, 9. [CrossRef] [PubMed]

57. Mamani, J.I.; Pacheco, K.B.; Elorrieta, P.; Romoacca, P.; Castelan, H.; Davila, S.; Sierra, J.L.; Quispe-Ricalde, M.A. Draft Genome Sequence of Halomonas elongata MH25661 Isolated from a Saline Creek in the Andes of Peru. Microbiol. Resour. Announc. 2019, 8. [CrossRef] [PubMed]

58. Menes, R.J.; Viera, C.E.; Farías, M.E.; Seufferheld, M.J. Halomonas vilamensis sp. nov., isolated from high-altitude Andean lakes. Int. J. Syst. Evol. Microbiol. 2011, 61, 1211-1217. [CrossRef] [PubMed]

59. Xiao-Ran, J.; Jin, Y.; Xiangbin, C.; Guo-Qiang, C. Chapter Eleven-Halomonas and Pathway Engineering for Bioplastics Production. In Methods in Enzymology; Scrutton, N., Ed.; Academic Press: Cambridge, MA, USA, 2018; pp. 309-328.

60. Adkins, J.P.; Madigan, M.T.; Mandelco, L.; Woese, C.R.; Tanner, R.S. Arhodomonas aquaeolei gen. nov., sp. nov., an aerobic, halophilic bacterium isolated from a subterranean brine. Int. J. Syst. Bacteriol. 1993, 43, 514-520. [CrossRef] [PubMed]

61. Donachie, S.P.; Hou, S.; Gregory, T.S.; Malahoff, A.; Alam, M. Idiomarina loihiensis sp. nov., a halophilic $\gamma$-Proteobacterium from the Lō'ihi submarine volcano, Hawai'i. Int. J. Syst. Evol. Microbiol. 2003, 53, 1873-1879. [CrossRef] [PubMed]

62. Prado, B.; Del Moral, A.; Quesada, E.; Ríos, R.; Monteoliva-Sanchez, M.; Campos, V.; Ramos-Cormenzana, A. Numerical Taxonomy of Moderately Halophilic Gram-negative Rods Isolated from the Salar de Atacama, Chile. Syst. Appl. Microbiol. 1991, 14, 275-281. [CrossRef]

63. Minegishi, H.; Echigo, A.; Nagaoka, S.; Kamekura, M.; Usami, R. Halarchaeum acidiphilum gen. nov., sp. nov., a moderately acidophilic haloarchaeon isolated from commercial solar salt. Int. J. Syst. Evol. Microbiol. 2010, 60, 2513-2516. [CrossRef]

64. Rensing, C. Adaption to life at high salt concentrations in Archaea, Bacteria and Eukarya. Saline Syst. 2005, 1, 6. [CrossRef]

65. Sorokin, D.Y.; Messina, E.; Smedile, F.; Roman, P.; Damsté, J.S.S.; Ciordia, S.; Mena, M.C.; Ferrer, M.; Golyshin, P.N.; Kublanov, I.V.; et al. Discovery of anaerobic lithoheterotrophic haloarchaea, ubiquitous in hypersaline habitats. ISME J. 2017, 11, 1245-1260. [CrossRef]

66. Mou, Y.-Z.; Qiu, X.-X.; Zhao, M.-L.; Cui, H.-L.; Oh, D.; Dyall-Smith, M.L. Halohasta litorea gen. nov. sp. nov., and Halohasta litchfieldiae sp. nov., isolated from the Daliang aquaculture farm, China and from Deep Lake, Antarctica, respectively. Extremophiles 2012, 16, 895-901. [CrossRef]

67. Oren, A. Taxonomy of halophilic Archaea: Current status and future challenges. Extremophiles 2014, 18, 825-834. [CrossRef] [PubMed]

68. Williams, T.J.; Liao, Y.; Ye, J.; Kuchel, R.P.; Poljak, A.; Raftery, M.J.; Cavicchioli, R. Cold adaptation of the Antarctic haloarchaea Halohasta litchfieldiae and Halorubrum lacusprofundi. Environ. Microbiol. 2017, 19, 2210-2227. [CrossRef] [PubMed]

69. Fuchsman, C.A.; Collins, R.E.; Rocap, G.; Brazelton, W.J. Effect of the environment on horizontal gene transfer between bacteria and archaea. PeerJ 2017, 5, e3865. [CrossRef] [PubMed]

70. Pushkarev, A.; Inoue, K.; Larom, S.; Flores-Uribe, J.; Singh, M.; Konno, M.; Tomida, S.; Ito, S.; Nakamura, R.; Tsunoda, S.P.; et al. A distinct abundant group of microbial rhodopsins discovered using functional metagenomics. Nature 2018, 558, 595-599. [CrossRef] [PubMed]

71. Santos, F.; Yarza, P.; Parro, V.; Meseguer, I.; Rosselló-Móra, R.; Antón, J. Culture-Independent Approaches for Studying Viruses from Hypersaline Environments. Appl. Environ. Microbiol. 2012, 78, 1635-1643. [CrossRef] 
72. Garcia-Heredia, I.; Martin-Cuadrado, A.-B.; Mojica, F.J.M.; Santos, F.; Mira, A.; Antón, J.; Rodriguez-Valera, F. Reconstructing Viral Genomes from the Environment Using Fosmid Clones: The Case of Haloviruses. PLOS ONE 2012, 7, e33802. [CrossRef]

73. Ramos-Barbero, M.D.; Martínez, J.M.; Almansa, C.; Rodríguez, N.; Villamor, J.; Gomariz, M.; Escudero, C.; dC Rubin, S.; Antón, J.; Martínez-García, M.; et al. Prokaryotic and viral community structure in the singular chaotropic salt lake Salar de Uyuni. Environ. Microbiol. 2019, 21, 2029-2042. [CrossRef]

74. Weitz, J.S.; Wilhelm, S.W. Ocean viruses and their effects on microbial communities and biogeochemical cycles. F1000 Biol. Rep. 2012, 4. [CrossRef]

75. Roux, S.; Adriaenssens, E.M.; Dutilh, B.E.; Koonin, E.V.; Kropinski, A.M.; Krupovic, M.; Kuhn, J.H.; Lavigne, R.; Brister, J.R.; Varsani, A.; et al. Minimum Information about an Uncultivated Virus Genome (MIUViG). Nat. Biotechnol. 2019, 37, 29-37. [CrossRef]

76. Castelán-Sánchez, H.G.; Lopéz-Rosas, I.; García-Suastegui, W.A.; Peralta, R.; Dobson, A.D.W.; Batista-García, R.A.; Dávila-Ramos, S. Extremophile deep-sea viral communities from hydrothermal vents: Structural and functional analysis. Mar. Genom. 2019, 46, 16-28. [CrossRef]

77. Antunes, A.; Ngugi, D.K.; Stingl, U. Microbiology of the Red Sea (and other) deep-sea anoxic brine lakes. Environ. Microbiol. Rep. 2011, 3, 416-433. [CrossRef] [PubMed]

78. Claverie, J.-M.; Abergel, C. Mimiviridae: An Expanding Family of Highly Diverse Large dsDNA Viruses Infecting a Wide Phylogenetic Range of Aquatic Eukaryotes. Viruses 2018, 10, 506. [CrossRef] [PubMed]

79. Yau, S.; Lauro, F.M.; DeMaere, M.Z.; Brown, M.V.; Thomas, T.; Raftery, M.J.; Andrews-Pfannkoch, C.; Lewis, M.; Hoffman, J.M.; Gibson, J.A.; et al. Virophage control of antarctic algal host-virus dynamics. Proc. Natl. Acad. Sci. USA 2011, 108, 6163-6168. [CrossRef] [PubMed]

80. Le Romancer, M.; Gaillard, M.; Geslin, C.; Prieur, D. Viruses in extreme environments. In Life in Extreme Environments; Amils, R., Ellis-Evans, C., Hinghofer-Szalkay, H., Eds.; Springer Netherlands: Dordrecht, The Netherlands, 2007; pp. 99-113.

81. Buchalo, A.S.; Nevo, E.; Wasser, S.P.; Oren, A.; Molitoris, H.P. Fungal life in the extremely hypersaline water of the Dead Sea: ${ }^{\circledR}$ first records. Proc. R. Soc. Lond. Ser. B Biol. Sci. 1998, 265, 1461-1465. [CrossRef]

82. Gunde-Cimerman, N.; Zalar, P. Extremely Halotolerant and Halophilic Fungi Inhabit Brine in Solar Salterns around the Globe. Food Technol. Biotechnol. 2014, 52, 170-179.

83. Butinar, L.; Sonjak, S.; Zalar, P.; Plemenitaš, A.; Gunde-Cimerman, N. Melanized halophilic fungi are eukaryotic members of microbial communities in hypersaline waters of solar salterns. Bot. Mar. 2005, 48. [CrossRef]

84. Lahav, R.; Fareleira, P.; Nejidat, A.; Abeliovich, A. The Identification and Characterization of Osmotolerant Yeast Isolates from Chemical Wastewater Evaporation Ponds. Microb. Ecol. 2002, 43, 388-396. [CrossRef]

85. Asem, A.; Eimanifar, A.; Wink, M. Update of "Biodiversity of the Hypersaline Urmia Lake National Park (NW Iran)". Diversity 2016, 8, 6. [CrossRef]

86. Tkavc, R.; Matrosova, V.Y.; Grichenko, O.E.; Gostinčar, C.; Volpe, R.P.; Klimenkova, P.; Gaidamakova, E.K.; Zhou, C.E.; Stewart, B.J.; Lyman, M.G.; et al. Prospects for Fungal Bioremediation of Acidic Radioactive Waste Sites: Characterization and Genome Sequence of Rhodotorula taiwanensis MD1149. Front. Microbiol. 2018, 8. [CrossRef]

87. Jünemann, S.; Kleinbölting, N.; Jaenicke, S.; Henke, C.; Hassa, J.; Nelkner, J.; Stolze, Y.; Albaum, S.P.; Schlüter, A.; Goesmann, A.; et al. Bioinformatics for NGS-based metagenomics and the application to biogas research. J. Biotechnol. 2017, 261, 10-23. [CrossRef]

88. McNair, K.; Edwards, R.A. Genome Peek-An online tool for prokaryotic genome and metagenome analysis. PeerJ 2015, 3, e1025. [CrossRef] [PubMed]

89. Kindzierski, V.; Raschke, S.; Knabe, N.; Siedler, F.; Scheffer, B.; Pflüger-Grau, K.; Pfeiffer, F.; Oesterhelt, D.; Marin-Sanguino, A.; Kunte, H.J. Osmoregulation in the Halophilic Bacterium Halomonas elongata: A Case Study for Integrative Systems Biology. PLoS ONE 2017, 12, e0168818. [CrossRef] [PubMed]

90. Ren, M.; Zhang, Z.; Wang, X.; Zhou, Z.; Chen, D.; Zeng, H.; Zhao, S.; Chen, L.; Hu, Y.; Zhang, C.; et al. Diversity and Contributions to Nitrogen Cycling and Carbon Fixation of Soil Salinity Shaped Microbial Communities in Tarim Basin. Front. Microbiol. 2018, 9. [CrossRef] [PubMed]

91. Mobberley, J.M.; Authement, R.N.; Segall, A.M.; Paul, J.H. The Temperate Marine Phage $\Phi H A P-1$ of Halomonas aquamarina Possesses a Linear Plasmid-Like Prophage Genome. J. Virol. 2008, 82, 6618-6630. [CrossRef] [PubMed] 
92. Oren, A. Microbial life at high salt concentrations: Phylogenetic and metabolic diversity. Saline Syst. 2008, 4, 2. [CrossRef]

93. Rhodes, M.E.; Spear, J.R.; Oren, A.; House, C.H. Differences in lateral gene transfer in hypersaline versus thermal environments. BMC Evol. Biol. 2011, 11, 199. [CrossRef]

94. Reed, C.J.; Lewis, H.; Trejo, E.; Winston, V.; Evilia, C. Protein Adaptations in Archaeal Extremophiles. Archaea 2013, 2013. [CrossRef]

95. Becker, E.A.; Seitzer, P.M.; Tritt, A.; Larsen, D.; Krusor, M.; Yao, A.I.; Wu, D.; Madern, D.; Eisen, J.A.; Darling, A.E.; et al. Phylogenetically Driven Sequencing of Extremely Halophilic Archaea Reveals Strategies for Static and Dynamic Osmo-response. PLOS Genet. 2014, 10, e1004784. [CrossRef]

96. Srivastava, P.; Kowshik, M. Mechanisms of Metal Resistance and Homeostasis in Haloarchaea. Archaea 2013, 2013, 732864. [CrossRef]

97. Spooner, R.; Yilmaz, Ö. The Role of Reactive-Oxygen-Species in Microbial Persistence and Inflammation. Int. J. Mol. Sci. 2011, 12, 334-352. [CrossRef]

98. Lipson, D.A.; Haggerty, J.M.; Srinivas, A.; Raab, T.K.; Sathe, S.; Dinsdale, E.A. Metagenomic Insights into Anaerobic Metabolism along an Arctic Peat Soil Profile. PLoS ONE 2013, 8, e64659. [CrossRef] [PubMed]

99. Jones, D.L.; Baxter, B.K. DNA Repair and Photoprotection: Mechanisms of Overcoming Environmental Ultraviolet Radiation Exposure in Halophilic Archaea. Front. Microbiol. 2017, 8. [CrossRef] [PubMed]

100. Plominsky, A.M.; Henríquez-Castillo, C.; Delherbe, N.; Podell, S.; Ramirez-Flandes, S.; Ugalde, J.A.; Santibañez, J.F.; van den Engh, G.; Hanselmann, K.; Ulloa, O.; et al. Distinctive Archaeal Composition of an Artisanal Crystallizer Pond and Functional Insights Into Salt-Saturated Hypersaline Environment Adaptation. Front. Microbiol. 2018, 9. [CrossRef] [PubMed]

101. Kinoshita, E.; van der Linden, E.; Sanchez, H.; Wyman, C. RAD50, an SMC family member with multiple roles in DNA break repair: How does ATP affect function? Chromosome Res. Int J. Mol. Supramol. Evol. Asp. Chromosome Biol. 2009, 17, 277-288. [CrossRef]

102. de Souza, R.F.; Iyer, L.M.; Aravind, L. Diversity and evolution of chromatin proteins encoded by DNA viruses. Biochim. Biophys. Acta 2010, 1799, 302-318. [CrossRef]

103. Ramírez-Orozco, M.; Serrano-Pinto, V.; Ochoa-Álvarez, N.A.; Makarov, R.Y.; Martínez-Díaz, S.F. Genome sequence analysis of the Vibrio parahaemolyticus lytic bacteriophage VPMS1. Arch. Virol. 2013, 158, 2409-2413. [CrossRef]

104. Gao, E.-B.; Huang, Y.; Ning, D. Metabolic Genes within Cyanophage Genomes: Implications for Diversity and Evolution. Genes 2016, 7, 80. [CrossRef]

105. Cabello, P. Nitrate reduction and the nitrogen cycle in archaea. Microbiology 2004, 150, 3527-3546. [CrossRef]

106. DasSarma, S.; DasSarma, P. Halophiles. eLS 2017. [CrossRef]

107. He, T.; Li, H.; Zhang, X. Deep-Sea Hydrothermal Vent Viruses Compensate for Microbial Metabolism in Virus-Host Interactions. MBio 2017, 8. [CrossRef]

108. Andrei, A.-Ş.; Banciu, H.L.; Oren, A. Living with salt: Metabolic and phylogenetic diversity of archaea inhabiting saline ecosystems. FEMS Microbiol. Lett. 2012, 330, 1-9. [CrossRef] [PubMed]

109. Liu, Y.; Beer, L.L.; Whitman, W.B. Sulfur metabolism in archaea reveals novel processes. Environ. Microbiol. 2012, 14, 2632-2644. [CrossRef] [PubMed]

110. Yau, S.; Lauro, F.M.; Williams, T.J.; DeMaere, M.Z.; Brown, M.V.; Rich, J.; Gibson, J.A.; Cavicchioli, R. Metagenomic insights into strategies of carbon conservation and unusual sulfur biogeochemistry in a hypersaline Antarctic lake. ISME J. 2013, 7, 1944-1961. [CrossRef] [PubMed]

(C) 2019 by the authors. Licensee MDPI, Basel, Switzerland. This article is an open access article distributed under the terms and conditions of the Creative Commons Attribution (CC BY) license (http://creativecommons.org/licenses/by/4.0/). 